\title{
Cardiac metabolism - A promising therapeutic target for heart failure
}

Hannah Noordalia ${ }^{a}$ Brodie L Loudon ${ }^{b}$, Michael P Frenneaux ${ }^{b}$, and Melanie Madhani ${ }^{a}$

a Institute of Cardiovascular Sciences, University of Birmingham, Birmingham, UK

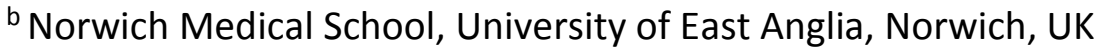

\section{Address for Correspondence:}

Dr Melanie Madhani (Corresponding Author)

Institute of Cardiovascular Sciences

College of Medical and Dental Sciences

University of Birmingham

Edgbaston, Birmingham B15 2TT

Tel: 01214146897

Email: M.Madhani@bham.ac.uk 


\section{Abstract}

Both heart failure with reduced ejection fraction (HFrEF) and with preserved ejection fraction (HFpEF) are associated with high morbidity and mortality. Although many established pharmacological interventions exist for HFrEF, hospitalization and death rates remain high, and for those with HFpEF (approximately half of all heart failure patients), there are no effective therapies. Recently, the role of impaired cardiac energetic status in heart failure has gained increasing recognition with the identification of reduced capacity for both fatty acid and carbohydrate oxidation, impaired function of the electron transport chain, reduced capacity to transfer ATP to the cytosol, and inefficient utilization of the energy produced. These nodes in the genesis of cardiac energetic impairment provide potential therapeutic targets, and there is promising data from recent experimental and early-phase clinical studies evaluating modulators such as carnitine palmitoyltransferase 1 inhibitors, partial fatty acid oxidation inhibitors and mitochondrial-targeted antioxidants. Metabolic modulation may provide significant symptomatic and prognostic benefit for patients suffering from heart failure above and beyond guideline-directed therapy, but further clinical trials are needed.

\section{Keywords:}

Cardiac metabolism; Heart failure; Heart failure with reduced ejection fraction (HFrEF); Heart failure with preserved ejection fraction (HFpEF); Metabolic modulation 


\section{Table of Contents}

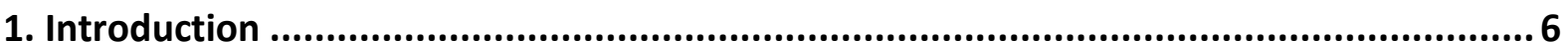

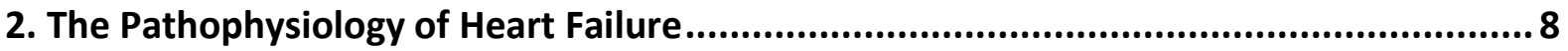

3. Cardiac Metabolism and Energetic Status in the Normal Heart and in Heart Failure ..... 15

4. Metabolic Modulators: Promising Therapeutic Agents .......................................... 30

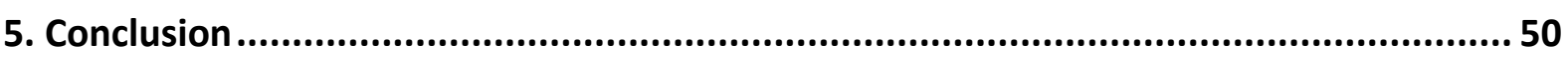

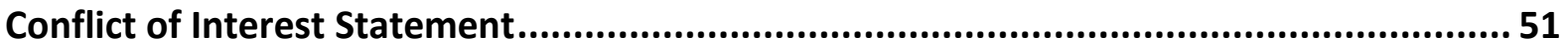

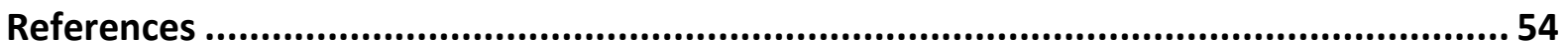

Figures:

Figure 1: An Overview of Cardiac Metabolism in the Healthy Heart ..............................552

Figure 2: An Overview of Cardiac Metabolism in the Failing Heart and Targets of Metabolic

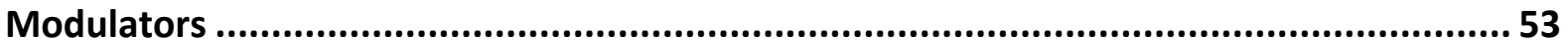

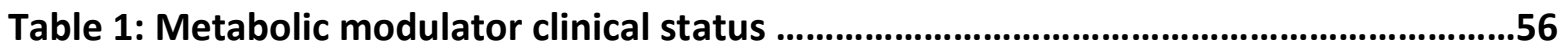




\section{Abbreviations}

ACE

Angiotensin converting enzyme

ADP Adenosine diphosphate

ATP Adenosine triphosphate

BNP Brain natriuretic peptide

cGMP cyclic guanosine monophosphate

CK Creatine kinase

CO Cardiac output

CoA Coenzyme A

CoQ10 Coenzyme Q10

CPT Carnitine palmitoyltransferase

DCA Dichloroacetate

ETC Electron transport chain

FA Fatty acid

$\mathrm{FADH}_{2} \quad$ Flavin adenine dinucleotide

GIK Glucose-Insulin-Potassium

HCM Hypertrophic cardiomyopathy

HF Heart failure

HFpEF Heart failure with preserved ejection fraction

HFrEF Heart failure with reduced ejection fraction

LVEF Left ventricular ejection fraction

MCD Malonyl-CoA decarboxylase

$\mathrm{NADH} \quad$ Nicotinamide adenine dinucleotide

NO Nitric oxide 
NYHA New York Heart Association

PDH Pyruvate dehydrogenase

PDK Pyruvate dehydrogenase kinase

$\mathrm{PCr} \quad$ Phosphocreatine

PDE Phosphodiesterase

RAAS Renin-angiotensin-aldosterone-system

ROS Reactive oxygen species

SS31 Szeto-Schiller peptide 31

TAC Transverse aortic constriction

TCA Tricarboxylic acid 


\section{Introduction}

Chronic heart failure (HF) is a highly prevalent, multi-system disorder, which affects over 23 million people worldwide (Bui, et al., 2011). The cardiovascular system ensures that blood supply matches the metabolic demands of the body. In HF, the reserve of the cardiovascular system is overwhelmed due to dysfunction of the cardiac muscle, which is characterized by defects in ventricular active- and passive-filling, and contraction. In milder cases, this impairment may only be present on exertion, when contractile and filling reserve are recruited to increase cardiac output (CO), but in more severe cases, $\mathrm{CO}$ may be insufficient even at rest. The HF syndrome may occur secondary to a range of cardiovascular insults, including myocardial infarction and chronic arterial hypertension, and whilst most prevalent in the elderly, it may occur at any age (van Riet, et al., 2016).

Patients with HF are grouped into phenotypic variants based on left ventricular ejection fraction (LVEF), a measure which is easily obtained via non-invasive transthoracic echocardiography that in HFrEF correlates strongly with HF mortality (Solomon, et al., 2005). Ejection fraction is not simply a measure of cardiac contractile function, but is influenced by ventricular size and by vasculoventricular (V-V) coupling (Borlaug \& Kass, 2011). Just over half of patients with HF have an EF $>50 \%$ and are said to have heart failure with preserved ejection fraction (HFpEF). Less than half of patients with $\mathrm{HF}$ have an $\mathrm{EF}<40 \%$ and are said to have heart failure with reduced ejection fraction (HFrEF). Interestingly, $10-20 \%$ of patients with HF have a mid-range LVEF (HFmEF) between 40 and $50 \%$, some of whom have 'recovered' function, and this syndrome is now becoming increasingly recognized as a separate entity to HFrEF and HFpEF, bearing similarities with the latter (Nadruz, et al., 2016). 
The HF syndrome may manifest clinically as dyspnea, fatigue, exercise intolerance, and peripheral oedema. HFpEF is characterized by raised left ventricular end diastolic pressure (LVEDP) due to diastolic dysfunction, however there is also evidence in many patients of systolic dysfunction (despite the normal LVEF). Furthermore, as in HFrEF, there is frequently chronotropic incompetence, impaired peripheral vascular function and neurohormonal activation (Bursi, et al., 2006; Kitzman, et al., 2002; Yancy, et al., 2006). HFrEF and HFpEF affect distinct patient groups, and therapies that have been shown to significantly improve mortality in HFrEF have failed to show similar benefits in HFpEF, despite many being targeted at maladaptive responses common to both (Kitzman, et al., 2010; Massie, et al., 2008; Yusuf, et al., 2003). The guideline-directed therapies employed in HFrEF have been reviewed extensively (Lother \& Hein, 2016; Loudon, et al., 2016), and are aimed at reducing neurohormonal activation (e.g. $\beta$-adrenergic receptor antagonists; angiotensin converting enzyme $[A C E]$ inhibitors; angiotensin II receptor blockers [ARB]; mineralocorticoid receptor antagonists [MRA]; neprilysin inhibitor-ARB combination drugs) and correcting volume overload (diuretics) and altered haemodynamics (vasodilators and inotropic agents; Ponikowski, et al., 2016; Yancy, et al., 2013). There are currently no evidence-based therapies for HFpEF, and despite the range of therapies available in $\mathrm{HFrEF}$, the prognosis remains poor (Owan, et al., 2006), thus demonstrating an urgent need for new therapies in both conditions.

There has been increasing interest in the role of energetic impairment in the etiology, pathophysiology, and progression of HF (Hunter, et al., 2016; Neubauer, 2007; Pascual \& Coleman, 2016), and in agents that may correct this, by altering cardiac substrate utilization; improving mitochondrial electron transport chain (ETC) function; or increasing energy 
transfer from the mitochondrion to the cytosol (Siddiqi, et al., 2013). Agents have shown promise in HFrEF, include trimetazidine and perhexiline. Intravenous dichloroacetate (DCA) has been show to improve cardiac output via improved mechanical efficiency. Other metabolic agents are yet to be evaluated, whilst others are yet to show any benefit (Chong, et al., 2016). In this review, we will briefly outline the pathophysiology of HF, focusing on metabolic disturbances, and discuss the current evidence behind therapeutic agents used to correct metabolic dysfunction.

\section{The Pathophysiology of Heart Failure}

\subsection{Heart Failure with Reduced Ejection Fraction}

HFrEF typically occurs as a result of an acute insult (e.g myocardial infarction), a chronic insult (e.g. hypertension, valvular heart disease), or may be a consequence of autoimmune/infective causes, genetic mutations, or infiltrations/depositions (e.g sarcoidosis, amyloidosis). A severe reduction in EF is representative of a reduction in contractile function, maladaptive ventricular remodeling, and dysfunctional vasculoventricular and interventricular coupling (Kass, et al., 1987; Ky, et al., 2013). This translates to an increase in LVEDP and left ventricular end diastolic volume (LVEDV). Recruitment of the intrinsic Frank-Starling mechanism due to increased LVEDV blunts the fall in stoke volume (SV) at rest in less severe cases, but there is an inability to increase SV on exercise, especially in the presence of coronary artery lesions (Lele, et al., 1996; Sumimoto, et al., 1997). In more severe cases SV may also be substantially reduced at rest. The force-frequency relation is also flat or even negative in HFrEF (Gwathmey, et al., 1987), which contributes to the fall in CO reserve. Deficient cardiovascular reserve culminates in 
exercise intolerance and in more severe cases severe HF develops at rest resulting in hospitalization, which is often recurrent.

End-organ hypoperfusion (e.g. renal hypoperfusion or ischemia of neurons in the hypothalamic paraventricular nucleus [PVN]; Sharma, et al., 2016) and baroreflex impairment activate neurohormonal compensatory mechanisms. These attempt to retain salt and water (increasing preload to recruit the Frank-Starling mechanism), cause vasoconstriction to maintain cerebral perfusion pressure, and increase cardiac inotropic, chronotropic, and lusitropic function. These mechanisms include sympathetic nervous system activation and inhibition of vagal activity (Jackson, et al., 2000), activation of the renin-angiotensin-aldosterone system (RAAS), and release of the osmoregulatory hormone vasopressin. Angiotensin II has also been shown to activate neurons in the PVN to further increase sympathetic tone (Chen, et al., 2011). Chronically however, elevated catecholamines are arrhythmogenic and toxic, due to cyclic adenosine monophosphate (cAMP)-mediated calcium overload which is pro-apoptotic (Mann, et al., 1992). Sensitivity of cardiac muscle to $\beta$-adrenergic stimulation is also reduced in HFrEF, with a reduction in $\beta 1$ receptor density (Bristow, et al., 1982) and desensitization of receptors (either directly via PKA or G protein-coupled receptor kinase dependent phosphorylation, or via eNOScoupling; Lohse, 1995) which, coupled with autonomic dysfunction, contributes to chronotropic incompetence, further worsening exercise intolerance.

A raised LVEDV causes progressive LV cavity dilatation, which increases wall stress (afterload) according to Laplace's law. Ventricular wall stress/stretch further activates the RAAS to compensate, and the local, tissue effects of chronic pro-hypertrophic angiotensin II 
promotes remodeling by way of increased protein synthesis, interstitial fibrosis, and inflammation (Paul, et al., 2006). Pathological remodeling of the electrical system also occurs, often leading to left bundle branch block (LBBB) and ventricular dyssynchrony. These structural changes contribute to a reduction in left ventricular contractility as represented by end systolic elastance (Ees), the slope of the left ventricular end systolic pressure-volume relation (ESPVR). The gold-standard for the assessment of $\mathrm{V}-\mathrm{V}$ coupling is via analysis of invasive pressure-volume recordings to create PV loops. If obtained during progressive IVC balloon-occlusion, one can plot the end systolic pressure (ESP) for each loop to create the linear ESPVR and calculate its slope, the Ees, a relatively load-independent measure of systolic function (Gillebert, et al., 1997). Ees may also be estimated from a non-invasive single beat method using echocardiography, which correlates well with invasive measures (Chen, et al., 2001). Arterial elastance (Ea), a grouped measure of both pulsatile and static components of afterload, may also be calculated as the negative slope of a line drawn from the ESP to the end diastolic volume (EDV) on the volume $(x)$ axis, representing ESP/SV (Kelly, et al., 1992). The ratio of Ea/Ees reflects V-V coupling, which is maximized for mechanical efficiency between a range of 0.3 and 1.3 (De Tombe, et al., 1993). In HFrEF, the V-V coupling ratio may be raised outside of this range due to a fall in the Ees secondary to the inciting cardiac insult, and as a result these patients respond well to afterload reduction with vasodilators and diuretics, showing an improvement in SV with relatively small changes in systolic blood pressure (Schwartzenberg, et al., 2012). V-V coupling ratio (but not Ees alone) and left ventricular size each correlate strongly with prognosis in HFrEF (Ky, et al., 2013). 


\subsection{Heart Failure with Preserved Ejection Fraction}

HFpEF tends to occur in women more so than men, and in older, hypertensive patients with a wide range of cardiovascular comorbidities including the metabolic syndrome, diabetes mellitus, obesity, and endothelial dysfunction (Borlaug \& Paulus, 2011). The observed features of diastolic dysfunction and systemic hypertension were initially taken as evidence that HFpEF is primarily caused by static 'afterload excess' (Hart, et al., 2001). However, early stage HFpEF is instead considered a disorder of depleted cardiovascular reserve, with exercise testing required to confirm the diagnosis outside of acute decompensation (Borlaug, et al., 2010; Obokata, et al., 2016). Given the diversity of cardiovascular conditions associated with HFpEF and the identification of distinct phenotypes of the syndrome, it is generally accepted that HFPEF represents a range of diseases rather than a single distinct entity (Lindman, et al., 2014; Shah, et al., 2016), which further complicates the testing of new potential therapies. Indeed, it has recently been suggested that treatment of HFpEF should be targeted at components of the disease (e.g. statins for systemic inflammation and caloric restriction for metabolic syndrome), which would individualize therapy based on HFpEF phenotype (Shah, et al., 2016). HFpEF contains many features that are common to HFrEF (i.e. common to all HF), due to the limited range of responses available to the cardiovascular system. These features of HFpEF include diastolic dysfunction, impairment of systolic function and reserve, abnormal V-V coupling, inflammation and endothelial dysfunction, chronotropic incompetence and altered $\beta$-adrenergic signaling, pulmonary hypertension, renal disease, and altered cardiac and skeletal muscle metabolism (Sharma \& Kass, 2014). 
Recently, Paulus and Tschope (2013) outlined a novel paradigm for the pathophysiology of HFpEF, which centers on cardiovascular comorbidities and systemic inflammation culminating in reduced myocardial nitric oxide (NO) and cyclic guanosine monophosphate (cGMP) bioavailability due to reactive oxygen species (ROS)-related scavenging of NO (Paulus \& Tschope, 2013). Outside the myocardium, the effects of systemic inflammation in various tissues culminate in the pulmonary hypertension, muscle weakness, and sodium retention which contribute to HFpEF phenotypic diversity (Cowley, et al., 2015; Dhakal, et al., 2015). This paradigm identifies the subsequent reduction in protein kinase G (PKG) activity and uncontrolled inflammation as the basis for disease development and progression, leading to increased passive tension of cardiomyocytes second to hypophosphorylation of the massive cytoskeletal protein titin (Borbely, et al., 2009), uncontrolled hypertrophy, and interstitial collagen deposition (van Heerebeek, et al., 2006; van Heerebeek, et al., 2012; Westermann, et al., 2011). ROS-dependent oxidation of titin in HFpEF further compounds passive cardiomyocyte tension, despite an observed shift in titin isoform expression from predominance of the N2B isoform to the larger and more compliant N2BA isoform (Borbely, et al., 2005). In HFrEF, the inflammation occurs at the level of the cardiomyocyte, with the development of systemic inflammation being a late feature of the disease. This novel paradigm poses many important therapeutic questions, such as the potential for increased benefit from cardiovascular therapies with ancillary antiinflammatory properties, in terms of disease progression and prognosis. It also goes some way to explaining the recent positive results with inorganic nitrate and nitrite to supplement myocardial NO in HFpEF (Borlaug, et al., 2015; Borlaug, et al., 2016), and outlines a beneficial mechanism for the use of neprilysin inhibitor-ARB combination (ARNI) drugs in HFpEF beyond neurohormonal regulation, which has been otherwise unsuccessful in 
treating this disease (Yusuf, et al., 2003). The increased levels of natriuretic peptides following ARNI treatment activate myocardial natriuretic peptide receptors, which are linked to particulate guanylate cyclases, thus restoring cGMP bioavailability (von Lueder, et al., 2013).

As noted, LVEF is a grouped variable which represents a number of components such as contractile function, ventricular remodeling, and V-V coupling, and despite preservation of LVEF at rest, these components are usually all abnormal in HFpEF compared to healthy controls. Following improvements in imaging techniques, such as the development of straingauge echocardiography, evidence of mechanical dyssynchrony and subtle defects in longitudinal and radial systolic function have been identified (Tan, et al., 2009). Compared to HFrEF, the LV in HFpEF is typically hypertrophied with a normal LV cavity radius (and therefore lower wall stress), with lower serum natriuretic peptide levels and neurohormonal activation (Iwanaga, et al., 2006). However, the LV filling pressure, elevated due to reduced LV compliance, is therefore reflected back into the left atrium and pulmonary circulation in $\mathrm{HFpEF}$, increasing the incidence of atrial fibrillation, pulmonary hypertension and right ventricular dysfunction (Guazzi \& Borlaug, 2012). This increase in pulmonary capillary wedge pressure (PCWP) is markedly worsened on exercise. It is important to note that V-V coupling is also abnormal at rest in HFpEF, despite maintenance of the Ea/Ees ratio within the normal range (Borlaug, et al., 2009). The grouped measure of afterload stresses, Ea, is significantly elevated in these patients, due to calcific arterial stiffening (static component), and propagation of reflected waves from arterial impedance mismatch (pulsatile component) causing them to arrive in late systole rather than early diastole, further adding to LV afterload (Borlaug, et al., 2007; Kelly, et al., 1989). In response, the Ees (or ventricular 
stiffness) must increase to maintain mechanical efficiency, resulting in a normal Ea/Ees ratio. As a result, patients with HFpEF have impaired reserve of $\mathrm{V}-\mathrm{V}$ coupling, which is best demonstrated with invasive exercise testing. On exercise in health, the Ea increases slightly with a significantly greater increase in Ees, which causes the V-V coupling ratio to fall (and the inversely related LVEF to increase), increasing cardiac efficacy (Najjar, et al., 2004). On exercise in HFpEF, due to a loss of Ees reserve and a further increase in the already elevated Ea the ratio remains unchanged, reducing cardiac efficacy and increasing the energy cost of LV stroke work (Phan, et al., 2009). The increased slope of the ESPVR (Ees) also results in large changes in systolic blood pressure for a given change in LV end systolic volume (LVESV). As a result, patients with HFpEF are more 'volume sensitive' than those with HFrEF, with a narrow window observed between the extremes of pulmonary oedema and pre-renal failure with diuretic therapy (Gandhi, et al., 2001).

Whether altered metabolic function is a cause of HF or an effect is not always obvious. Energetic dysfunction may contribute to the natural histories of both HFrEF and HFpEF regardless of etiology. All HF (and indeed LV hypertrophy even in the absence of HF) has been shown to possess a component of altered cardiac and skeletal muscle metabolism, and the severity of this alteration correlates with disease progression (Neubauer, et al., 1992). Lower PCr/ATP ratios on phosphorous magnetic resonance spectroscopy ( ${ }^{31} \mathrm{P}$ MRS) compared to healthy controls have been demonstrated in patients with LV hypertrophy, $\mathrm{HFrEF}$, and HFpEF, manifest as a reduction in the ratio of resting cardiac PCr/ATP and in the case of skeletal muscle, a slowing of the rate of recovery of $\mathrm{PCr}$ following exercise (Neubauer, et al., 1992; Phan, et al., 2009). Several mechanisms contribute to this energetic impairment, including decreased efficiency of energy use, mechanical dyssynchrony, 
microvascular disease, downregulation of key metabolic enzymes, and impaired mitochondrial ETC function (Stanley, et al., 2005).

\section{Cardiac Metabolism and Energetic Status in the Normal Heart and in Heart Failure}

Under normal physiological conditions, the myocardium relies upon a constant supply of ATP to fuel its continuous contractile function and ion channel activity (primarily for myocardial calcium [ $\left.\mathrm{Ca}^{2+}\right]$ handling), cycling approximately 6 kg per day (Neubauer, 2007; see Fig 1). During the fasting state, approximately $70 \%$ of cardiac ATP production is achieved through free fatty acid (FA) metabolism, with approximately $20 \%$ being produced via carbohydrate metabolism and the remaining through the oxidation of ketones, lactate, and amino acids (Bing, et al., 1954; Lopaschuk, et al., 1994). There is a wealth of evidence showing significant shifts in cardiac metabolism and subsequent impairment of energetic status in HF; indeed, severe metabolic imbalance is recognized as an integral feature of the disease (Doenst, et al., 2013). Explanted failing human hearts, and rat hearts with coronary artery ligation induced-HF, have dramatically lower levels of $\mathrm{PCr}$ than healthy controls (Neubauer, et al., 1999). Smith and colleagues (2006) quantified a 35\% decrease in cardiac $\mathrm{PCr}$ in patients with LV hypertrophy (Smith, et al., 2006). Other models of HF, such as a porcine model of pressure-overload-induced HF (Jameel, et al., 2016) and a canine model of tachycardia induced HF (Xiong, et al., 2015), have shown similar results.

$\mathrm{PCr} / \mathrm{ATP}$ ratio, obtained via in vivo non-invasive ${ }^{31} \mathrm{P} \mathrm{MRS}$, was found to be reduced in patients with HFrEF due to dilated cardiomyopathy (DCM) and the magnitude of this reduction correlated with New York Heart Association (NYHA) functional class and mortality (Neubauer, et al., 1997). Reduced PCr/ATP ratio has been reported in a wide range of 
cardiomyopathies including hypertrophic cardiomyopathy (HCM), the commonest inherited cardiac condition worldwide, and these changes preceded hypertrophy in many cases (de Roos, et al., 1992). Our group has also demonstrated a significant reduction in cardiac PCr/ATP ratio in patients with HFpEF, and this reduced energetic reserve is likely responsible for the dynamic slowing of LV active relaxation and inability to improve (reduce) V-V coupling ratio during exercise observed in these patients (Phan, et al., 2009). The use of dynamic (exercise) ${ }^{31} \mathrm{P}$ MRS allows for quantification of $\mathrm{PCr}$ recovery kinetics in skeletal muscle, such as $\mathrm{PCr}$ recovery rate, which is prolonged in HF (Chance, et al., 2006). Postexercise $\mathrm{PCr}$ recovery rate $(\mathrm{KPCr})$ represents the replenishment of the cytosolic $\mathrm{PCr}$ pool from ATP produced at the ETC, which is a marker of mitochondrial oxidative capacity.

Recently, Cunningham and colleagues demonstrated the feasibility of hyperpolarizedcarbon metabolic magnetic resonance spectroscopy $\left({ }^{13} \mathrm{C} \mathrm{MRS}\right)$ in man, following a 0.1 $\mathrm{mmol} \cdot \mathrm{kg}^{-1}$ dose of hyperpolarized $\left[1-{ }^{13} \mathrm{C}\right]$ pyruvate in 4 healthy subjects (Cunningham, et al., 2016). ${ }^{13} \mathrm{C}$ MRS of the heart has the distinct advantage over ${ }^{31} \mathrm{P}$ MRS of providing real-time data relating to the in vivo metabolism of pyruvate, upstream of the ETC. This technique allows for appreciation of the various fates of pyruvate through anaerobic glycolysis or mitochondrial oxidation, by measuring ${ }^{13} \mathrm{C}$-tagged metabolites (e.g. bicarbonate, lactate, and alanine) immediately following intravenous administration (Merritt, et al., 2007). This represents an exciting new avenue for expanding our understanding of cardiac metabolism and energetic status, and for testing novel therapies.

There are several mechanisms that contribute to the energetic impairment observed in HF. These may include microvascular dysfunction or ischemia, energy-wasting mechanisms, 
impairment of energy transfer to the point of utilization within the cytosol, increased oxidative stress, and defective energy extraction from available substrates. Ischemia/hypoxia in the failing ventricle (with poor reserve) is worsened by tachycardia (such as with exercise or with $\mathrm{AF}$, which has a high prevalence in $\mathrm{HF}$ ), with a reduction in diastolic filling where the majority of coronary flow occurs. In HF, myocardial oxygen supply may be further affected by the previously mentioned shift of reflected aortic waves to late systole rather than early diastole (due to increased pulse wave velocity in the stiff aorta), augmenting systolic blood pressure (afterload) and reducing myocardial perfusion pressure during diastole (Borlaug, et al., 2007).

Hypertrophic growth may also be considered an energy 'sink', requiring the rerouting of glycolytic intermediates and other metabolic by-products to support substantial protein synthesis. Other mechanisms that may 'waste' energy include intra-ventricular dyssynchrony (demonstrated by altered strain gauge imaging; Phan, et al., 2009), interventricular dyssynchrony e.g diastolic ventricular interaction (Atherton, et al., 1997), and detoxification of ROS and nitrosative stress. Energy transfer from the mitochondria to the sites of utilization within the cytosol is also impaired in HF due to changes in the CK system (Ingwall, 1984), including reduced sodium $\left(\mathrm{Na}^{+}\right)$-creatine cotransporter protein content (Neubauer, et al., 1999) and impaired cytosolic CK activity due to oxidative stress (VenturaClapier, et al., 2011). Perhaps the most complex mechanism, and one which offers numerous potential pharmacological targets for metabolic modulation in $\mathrm{HF}$, is that of altered substrate metabolism (Fig 2). Metabolism in advanced HF is thought to revert back to the fetal metabolic profile, with a decrease in FA metabolism despite preserved cytosolic FA uptake, and a shift towards glucose uptake and glycolysis (Fillmore \& Lopaschuk, 2013; 
Pascual \& Coleman, 2016). However, there is evidence to show that terminal oxidation of both FA and glucose by the mitochondria is downregulated in HF, with compensatory funneling of pyruvate into anaplerotic pathways and increased ketone metabolism (Aubert, et al., 2016).

\subsection{Fatty acid metabolism}

Free FA enters the myocardium from the bloodstream either passively or through facilitated uptake by FA transporters (mainly CD36) and plasma membrane FA binding proteins. Within the cardiomyocytes, the short and long chain FAs are esterified into short chain fatty acyl coenzyme A (CoA) or long chain fatty acyl-CoA, respectively. The short chain fatty acyl CoA diffuses through the inner mitochondrial membrane into the mitochondria, however long chain fatty acyl CoA must first enter the 'carnitine shuttle' (van der Vusse, et al., 2000). The carnitine shuttle involves the addition of carnitine to long chain acyl CoA esters by the enzyme carnitine palmitoyltransferase 1 (CPT1) to generate long chain acyl carnitine, which is able to cross the outer mitochondrial membrane. CPT1 is thus the rate-limiting enzyme in long chain fatty acid metabolism. At the inner mitochondrial membrane, the enzyme CPT2 cleaves the carnitine off, which is then re-exported across the mitochondrial membrane.

Entry of long chain fatty acyl CoA into the mitochondria via CPT1 is regulated by excess tricarboxylic acid (TCA) cycle intermediates in times of energy excess, and by AMP-activated protein kinase (AMPK) in times of low cellular energy content. Excess citrate from the TCA cycle is transported into the cytosol where it is converted to acetyl CoA and oxaloacetate by ATP citrate lyase (Hue \& Taegtmeyer, 2009). Cytosolic acetyl CoA is further converted to malonyl CoA by the enzyme acetyl CoA carboxylase (ACC), which may be converted back 
into acetyl CoA by malonyl CoA decarboxylase (MCD). Malonyl CoA is a naturally occurring inhibitor of CPT1, thus carefully regulating the entry of free FAs into the mitochondria, as excess FA may react with mitochondrial ROS to produce lipid peroxides which damage mitochondrial DNA (Schrauwen, et al., 2001). AMPK activation by AMP in low energy states inhibits ACC and reduces malonyl CoA levels (thereby relieving inhibition of CPT1) and increases FA entry into the mitochondria to be oxidized by the $\beta$-oxidation machinery. AMPK also recruits CD36 to the sarcolemma, increasing cellular FA uptake (Samovski, et al., 2015).

Once inside the mitochondria, the long chain acyl CoA molecule undergoes a number of oxidation steps known as $\beta$-oxidation, ultimately generating acetyl $\operatorname{CoA}$, nicotinamide adenine dinucleotide (NADH) and flavin adenine dinucleotide $\left(\mathrm{FADH}_{2}\right)$. Acetyl CoA then enters the TCA cycle. $\beta$-oxidation enzymes are regulated by the peroxisome proliferator activated receptor (PPAR) family of transcription factors, PPAR $\alpha$ and $\beta / \delta$ (Gilde, et al., 2003). PPAR $\alpha$ also upregulates pyruvate dehydrogenase kinase (PDK) 4 in the myocardium which inhibits pyruvate dehydrogenase (PDH) activity, the rate-limiting enzyme for pyruvate metabolism, an example of FA-glucose co-regulation (Wu, et al., 2001). A further member of the PPAR family, PPARy, which is expressed in the intestine and at high levels in adipose tissue, may also be activated within cardiomyocytes. In the heart, PPARy activation increases free FA and glucose uptake, and glycerolipid biosynthesis (Krishnan, et al., 2009). PPARs are regulated by free FA and the transcriptional co-factor, PPAR $\gamma$ cofactor $1 \alpha$ (PGC1 $\alpha$ ), which is a master regulator of mitochondrial biogenesis (Handschin \& Spiegelman, 2008). PGC1 $\alpha$ is potently activated by cold and is therefore linked to the 'browning' of adipose tissue (by activating PPAR $\gamma$, which upregulates mitochondrial uncoupling protein 1 (UCP1) expression in adipocytes; Puigserver, et al., 1998). The activities of PGC1 $\alpha$ and AMPK 
are further regulated by the sirtuins (SIRT), a group of histone deacetylases which serve as 'anti-aging' enzymes and metabolic sensors that are activated by high $\mathrm{NAD}^{+} / \mathrm{NADH}$ ratios in states of energy depletion (Nemoto, et al., 2004; Oka, et al., 2015). SIRT-3 has been shown to phosphorylate and activate AMPK (Palacios, et al., 2009), and SIRT-1 has been shown to activate PGC1 $\alpha$ via deacetylation (Rodgers, et al., 2005).

In HF, there is reduced activity of the PPAR transcription-factor pathways, which results in downregulation of enzymes from the $\beta$-oxidation spiral (Pellieux, et al., 2006). A limitation in cardiac $\mathrm{O}_{2}$ supply may also limit FA oxidation, due to the relatively high cost of FA oxidation compared to glucose oxidation (Jaswal, et al., 2011). Furthermore, mitochondrial ROS and uncoupling of oxidative phosphorylation in HF lead to reduced production of ATP from FA oxidation (Tsutsui, et al., 2011). The energetic deficit also activates AMPK, which increases sarcolemmal expression of CD36, increasing FA entry into the cytosol. Coupled with lipolysis, and the subsequent liberation of FA from adipose tissue secondary to systemic neurohormonal activation, there is a resultant over-supply of free FA in the cardiomyocyte, which is prevented from entering terminal oxidation. Downregulation of the $\beta$-oxidation pathway was first identified in 1996 by Sack and colleagues in a study of left ventricular biopsies of patients with terminal HF and in rats with progressive LV hypertrophy, which demonstrated a $>40 \%$ decrease and $>70 \%$ decrease in the expression of $\beta$-oxidation enzymes, respectively (Sack, et al., 1996). A study by Neglia et al. (2007) also reported that in DCM patients with symptoms of HF, FA uptake and oxidation were reduced compared to the control group. Barger and colleagues observed a decrease in PPAR $\alpha$ gene expression and activity in hypertrophic rat cardiomyocytes and hearts from mice subjected to transverse aortic constriction (TAC; Barger, et al., 2000). PPAR $\alpha$ expression was also reduced 
in mice with HF induced by chronic angiotensin II stimulation, with a reduction in mRNA expression of enzymes involved in FA metabolism such as CPT1 (Pellieux, et al., 2006). PPAR $\alpha$ has been shown to be downregulated in failing human hearts (Karbowska, et al., 2003). PGC1 $\beta$ knock-out mice subjected to TAC experienced a rapid progression towards HF, extreme mitochondrial dysfunction, markedly reduced cardiac efficiency, and elevated levels of oxidative stress when compared to wild-type litter mates also subjected to TAC (Riehle, et al., 2011). Identical results have been found in PGC1 $\alpha$ deficient TAC-mice (Arany, et al., 2006; Lu, et al., 2010). However, Lionetti et al. found in a pacing-induced canine model of HF that PPAR $\alpha$ and PGC1 protein levels did not significantly differ from the control hearts (Lionetti, et al., 2005). SIRT-1 is also down-regulated in HF (Fukushima \& Lopaschuk, 2016). In spontaneously hypertensive rats, compensatory cardiac hypertrophy was accompanied by a decrease in SIRT-1 expression (Tang, et al., 2014). Similarly, SIRT-1 expression was reduced in patients with both compensated and decompensated HF (Akkafa, et al., 2015) and in patients with advanced HF (Lu, et al., 2014). In both of these studies, SIRT-1 downregulation was associated with an increase in oxidative stress and pro-apoptotic signaling. A decrease in SIRT-3 levels in hypertrophied TAC mouse hearts (Chen, et al., 2015) and SIRT-6 expression in human failing hearts (Sundaresan, et al., 2012) have also been reported; SIRT-6 deficient mice also developed hypertrophy and cardiac failure.

Recently, Shibayama and colleagues (2015) identified significant reductions in carnitine and FA levels in the mitochondria of canine hearts with pacing-induced HF (Shibayama, et al., 2015). Moreover, it has also been found that the expression and/or activity of other enzymes required for mitochondrial FA uptake and oxidation, such as muscle CPT1 and acylCoA synthetase are downregulated compared to controls (de Brouwer, et al., 2006; Lionetti, 
et al., 2005; Pellieux, et al., 2006). A reduction in FA uptake and oxidation was observed in HF induced by a high-salt diet in rats (Kato, et al., 2010) and in canines with tachycardia induced HF (Osorio, et al., 2002). In addition, FA oxidation rates and enzyme expression were reduced in rats subjected to abdominal aortic constriction to induce HF (Akki, et al., 2008). A reduction in myocardial carnitine has also been previously reported in patients with HCM and signs of chronic HF (Regitz, et al., 1990) as well as a decrease in FA oxidation in symptomatic DCM patients (Neglia, et al., 2007; Yazaki, et al., 1999). Interestingly, previous reports by Paolisso and colleagues demonstrated findings to the contrary, with HF patients having a $\sim 40 \%$ increase in FA uptake and oxidation despite no change in coronary blood flow (Paolisso, et al., 1994). It has therefore been suggested that the way in which HF is induced and HF severity in these studies may dictate the changes observed in metabolism (Doenst, et al., 2013), and this is also true for the alterations in carbohydrate metabolism.

It has been reported that triacylglycerol (TAG) pool dynamics are also dysregulated in the failing heart, with an associated rise in diacylglyceride (DAG) and ceramide, which have been implicated in lipotoxicity (Carley \& Lewandowski, 2016). The falling levels of long chain free FA from this altered TAG turnover lead to reduced signaling via the PPAR $\alpha$ pathway (as long chain free FA is an important ligand for PPAR $\alpha$ activation; Lahey, et al., 2014). O'Donnell et al. (2008) observed a significant reduction in TAG content and turnover in rats subjected to pressure-overload HF, due to an upregulation in the TAG hydrolase, and adipose triglyceride lipase enzyme (O'Donnell, et al., 2008). A reduction in TAG content and increased levels of toxic lipid intermediates were also found in patients with chronic HF, and this was successfully corrected following mechanical unloading with left ventricular assist device (LVAD) therapy (Chokshi, et al., 2012). Levels of toxic lipid intermediates have also been 
shown to be increased in rats subjected to TAC (Lahey, et al., 2014). The same group also identified that TAG turnover rate is also of critical importance in HF, rather than simply content, and normalizing TAG turnover rate via supplementation with the dietary FA oleate led to improved FA metabolism and contractile function in TAC rats (Lahey, et al., 2014). Thus, restoration of TAG dynamics, e.g. through supplementation of natural and dietary long-chain FAs, provide an additional therapeutic strategy in HF that warrants further investigation.

\subsection{Glucose metabolism}

Glucose enters the cardiomyocyte via the glucose transporters (GLUT1 and GLUT4). Following uptake, glucose is converted to glucose-6-phosphate (G6P) by hexokinase on the inner surface of the cell membrane, and this G6P enters the glycolytic pathway to generate pyruvate. G6P may also enter the pentose phosphate pathway (PPP) to produce NAD(P)H, which is essential for detoxifying cellular ROS (Ussher, et al., 2012). In addition, enzymes and products of the glycolytic pathway play an important role in cellular anabolism, as they may enter biosynthetic pathways such as the hexosamine biosynthetic pathway (HBP) to increase cellular biomass (Doenst, et al., 2013). Pyruvate from glycolysis is transported across the mitochondrial membrane by pyruvate translocase (an active, energy requiring process). Mitochondrial pyruvate is decarboxylated by the rate-limiting PDH complex, to form acetyl CoA, the common end-product of glucose oxidation and FA $\beta$-oxidation. PDH activity is regulated positively by PDH phosphatases and negatively by PDH kinases (Kolobova, et al., 2001), and is inhibited by its by-products acetyl CoA and NADH (Stanley, et al., 2005). A fall in mitochondrial ATP production such as in hypoxia or with mitochondrial dysfunction causes a fall in the cytosolic ATP/ADP ratio, which activates glycolysis 
(Maldonado \& Lemasters, 2014). In addition during hypoxia, breakdown of the ubiquitous hypoxia inducible factor $1 \alpha$ (HIF1 $\alpha$ ) by oxygen-dependent cytosolic prolyl hydroxylase is inhibited, resulting in HIF1 $\alpha$ accumulation and translocation to the nucleus (Lei, et al., 2008). HIF1 $\alpha$ upregulates the expression of PDK 1, inhibiting glucose oxidation, as well as GLUT4 and many enzymes involved in glycolysis, thus upregulating the precursors of the HBP and PPP (to detoxify hypoxia-generated ROS) and diverting pyruvate towards compensatory anaerobic glycolysis (to maintain ATP production), or anaplerosis. Chronic HIF1 $\alpha$ accumulation in hypertrophied hearts has also been shown to activate PPARy in cardiomyocytes, thus promoting glycerolipid formation via the glycerol-3-phosphate pathway, which causes TAG accumulation, apoptosis, and contractile dysfunction (Krishnan, et al., 2009).

Insulin resistance frequently occurs in HF (Ashrafian, Frenneaux et al., 2007) and reduces insulin-stimulated glucose uptake. However, uptake through insulin-independent GLUTsignaling may compensate (e.g. via AMPK signaling or GLUT1 upregulation), and most studies suggest that glucose uptake and glycolysis are maintained or increased in HF (Tenenbaum \& Fisman, 2004). However, in a rat TAC model of HF, despite increased glycolysis, there was no parallel increase in flux through the PDH enzyme complex, which led to the uncoupling of glycolysis from glucose oxidation (Sorokina, et al., 2007). Furthermore, the fall in glucose oxidation was accompanied by a compensatory increase in anaplerosis, to replace TCA intermediates which undergo terminal oxidation or are used for biosynthetic pathways as a result of hypertrophic remodeling in the failing heart. In combination, these mechanisms contribute to impaired energy generation from carbohydrate metabolism, despite the ready availability of glucose. Such findings have also been confirmed in a mouse 
TAC model (Dai, et al., 2012), and it has been suggested that this detrimental uncoupling of glycolysis and glucose oxidation can be exacerbated by reduced FA oxidation, due to the Randle cycle which further upregulates glycolysis (Fillmore \& Lopaschuk, 2013). Elevated levels of HIF1 $\alpha$, which occurs secondary to tissue hypoxia as discussed above, also contribute to the upregulation of glycolysis in HF (Holscher, et al., 2012).

In another mouse TAC study, cardiac glucose oxidation was found to be decreased by $66 \%$ (Zhabyeyev, et al., 2013), with a further study demonstrating a reduction in PDH activity and gene expression in HF, which may explain these findings (Lei, et al., 2004). Kato and colleagues induced chronic HF in Dahl salt-sensitive rats by implementing a high salt diet and observed a downregulation in gene expression of $\mathrm{PDH}$, as well as other proteins involved in glycolysis such as GLUT4, phosphofructokinase and phosphoglucomutase (Kato, et al., 2010). In rats with pressure overload induced HF, a progressive decline in glucose oxidation was observed (Doenst, et al., 2010). However, not all HF models demonstrate this. Osorio et al reported an increase in glucose oxidation rates in a canine model of rapid pacing-induced HF (Osorio, et al., 2002). Cellular glucose oxidation rates and $\beta$ oxidation rates are closely interrelated and closely regulate each other via the aforementioned 'Randle cycle'. The Randle cycle (Randle, et al., 1963) is the phenomenon whereby increased acetyl CoA from FA $\beta$-oxidation directly inhibits the PDH complex, as well as being transported to the cytosol and converted to citrate, which subsequently inhibits the ratelimiting glycolytic enzyme, phosphofructokinase. Conversely, when carbohydrate metabolism is increased, citrate from the tricarboxylic acid (TCA) cycle is transported to the cytoplasm where it is converted to acetyl CoA, and then into malonyl CoA which blocks CPT1, in turn decreasing FA metabolism. 


\subsection{Ketone metabolism}

Ketones are the most energy-efficient fuel available in the body, and are produced in the liver from excess acetyl-CoA produced from $\beta$-oxidation of FA. Ketone levels in health are therefore regulated by lipolysis (liberation of FA from TAG stores), amount of free FA reaching the hepatocyte, transport across the mitochondrial membrane (via diffusion or CPT1), and FA $\beta$-oxidation (Lopaschuk, et al., 2010). In the heart, as in all extrahepatic tissues, ketone bodies (acetoacetate, $\beta$-hydroxybutyrate, and acetone) undergo terminal oxidation following conversion back into acetyl CoA (in a series of reactions catalyzed by $\beta$ hydroxybutyrate dehydrogenase 1 [BHD1], succinyl CoA:3-oxoacid CoA transferase [SCOT], and mitochondrial acetyl-CoA acetyltransferase 1 [ACAT1]), or they may be redirected into lipogenic pathways, such as de novo lipogenesis via the enzymes ACC or fatty acid synthase (FAS), or the mevalonate pathway for cholesterol synthesis (Cotter, et al., 2013).

It has been recently identified that ketone metabolism is altered both in animal models of $\mathrm{HF}$ and in patients with HF. Aubert and colleagues reported an upregulation in the ketone oxidative enzyme BHD1 in TAC HF mice (Aubert, et al., 2016). These changes occurred in parallel to the downregulation of proteins involved in FA utilization, thus suggesting that the failing heart switches to ketone bodies as an alternative fuel source. Bedi and co-workers also observed significant increases in substrates involved in ketone metabolism in nondiabetic patients with advanced HFrEF (Bedi, et al., 2016). Ketongenic $\beta$-hydroxybutyryl-CoA levels, and $\beta$-hydroxybutyrate myocardial use, were markedly increased alongside decreases in myocardial lipid intermediates. The increase in ketone oxidation may have added effects on glucose and FA oxidation, as this could reduce the mitochondrial NAD $/ \mathrm{NADH}$ ratio and further inhibit $\beta$-oxidation enzymes such as long-chain 3-ketoacyl-CoA thiolase (LC 3-KAT; 
Jaswal, et al., 2011). These findings have garnered much attention in the HF metabolic field and have highlighted the need for further investigation into the role of altered ketone metabolism in order to determine whether the observed changes are beneficial and contribute to increased glucose oxidation, or are detrimental to cardiac function (Bedi, et al., 2016; Kolwicz, et al., 2016).

\subsection{The TCA cycle and oxidative phosphorylation}

Acetyl CoA from FA, glucose, ketone and amino acid metabolism enters the TCA cycle and generates $\mathrm{NADH}$ and $\mathrm{FADH}_{2}$ (Schwarz, et al., 2014). These donate high energy electrons which are transferred between electron acceptors (iron-sulfur subunits, quinone species, and flavin mononucleotide) within 4 enzyme complexes, I to IV, located within the mitochondrial inner membrane. This electron transfer powers extrusion of protons across the inner mitochondrial membrane, termed the electron transport chain (ETC). This subsequently activates ATP synthase, located on the inner mitochondrial membrane, which produces ATP through phosphorylation of adenosine diphosphate (ADP). There is concurrent oxidation of hydrogen ions to form water, and thus oxidation is coupled to phosphorylation. Oxidative phosphorylation is responsible for the production of over $95 \%$ of ATP in the myocardium (Beer, et al., 2002).

Due to the potential for premature electron leakage and subsequent binding with oxygen, the ETC is a site for the formation of ROS, which must be closely regulated in health to prevent overwhelming oxidative stress. Mitochondrial complexes I and III are well established as sites of superoxide production due to post-translational modification (Holmstrom \& Finkel, 2014), and hyperphosphorylation of complex IV may also contribute 
to increased ROS generation (Prabu, et al., 2006). At physiological levels, cellular ROS are signaling molecules in their own right via oxidation of key cellular proteins including enzymes (particularly those containing thiol moieties), either increasing or decreasing their activity (Hurd, et al., 2007). Furthermore, ROS produced at mitochondrial complex III at the onset of hypoxia inhibits prolyl hydroxylase, and is the primary mechanism for accumulation of the HIF1 $\alpha$ protein (Chandel, et al., 2000). At elevated levels, superoxide reacts with NO to form peroxynitrite. Peroxynitrite reduces tetrahydrobiopterin $(\mathrm{BH} 4)$ to $\mathrm{BH}$, which promotes uncoupling of endothelial nitric oxide synthase (eNOS; Milstien \& Katusic, 1999). Uncoupled eNOS becomes a source of further ROS production, rather than ROS-scavenging NO. Peroxynitrite and other ROS also directly damage mitochondrial DNA, which activates the nuclear enzyme poly ADP-ribose polymerase 1 (PARP-1; Pacher \& Szabo, 2007). NAD ${ }^{+}$is a key substrate of PARP-1, which is subsequently depleted, causing impairment of ATP production at the ETC and from glycolysis, leading to metabolic dysfunction, inflammation and cell death. Counter-regulatory mechanisms of mitochondrial ROS include uncoupling proteins (e.g. UCP2 and 3 in cardiomyocytes) and adenine nucleotide translocase (ANT), which balance charges at the mitochondrial intermembrane space to dissipate the electrochemical gradient, and mitochondrial superoxide dismutase (SOD) and $N A D(P) H$ which detoxify ROS (Azzu \& Brand, 2010; Circu \& Aw, 2010). The coordinated action of the respiratory chain complexes is dependent on their organization into functional units called respirasomes by the membrane phospholipid, cardiolipin (Szeto, 2014). Dissociation of the respirasomes leads to increased ROS generation and reduced ATP production (Lee \& Tian, 2015; Rosca \& Hoppel, 2013). 
HF culminates in impaired oxidative phosphorylation and ATP generation, both due to impaired substrate utilization and direct structural and functional changes in the mitochondria (Fillmore \& Lopaschuk, 2013). In a rat TAC model of HFrEF, Bugger and colleagues identified detrimental changes in mitochondrial morphology and volume density, accompanied by a 53\% decrease in expression of ETC proteins (Bugger, et al., 2010). In addition, the activity of the ETC complexes was found to be reduced in a canine rapid-pacing model of HF (Ide, et al., 1999) and in LV biopsies from patients with HF (Scheubel, et al., 2002). In some models of HF, organization of the ETC complexes into respirasomes appears to be impaired which may play an important role in electron slippage with ROS generation. This may be due to reduced expression of cardiolipin or altered interaction between cardiolipin and the respiratory complexes (Rosca \& Hoppel, 2013; Szeto, 2014). Increased ROS and oxidative stress increase compensatory UCP expression. Unfortunately, increased UCP expression also leads to an increase in heat generation with ATP generation, thereby rendering oxidative phosphorylation less efficient (Murray, et al., 2004). Murray and colleagues (2004) also identified that the elevated UCP levels were associated with increased circulating free FA levels in rats with chronically failing and infarcted hearts. UCP3 has also been shown to interact with other redox regulating proteins such as thioredoxin 2 (Trx2; Hirasaka, et al., 2011). It has been shown that Trx2 levels are reduced in the hearts of patients with DCM, and that Trx2 knock-out mice have a progressive decline in LV function leading to death by HF (Huang, et al., 2015). These effects may be related to the upregulation of TXNIP, which inhibits Trx2 (Chong, et al., 2014). In a mouse pressureoverload model of HF, TXNIP knock-out mice initially had reduced cardiac hypertrophy and preserved LV contractile reserve compared to their wild-type litter mates (Yoshioka, et al., 2012). 
As discussed, increased ROS in HF leads to compensatory activation of PARP-1 (Pacher \& Szabo, 2007). In a coronary artery ligation model of HF in rats, PARP-1 activation was increased alongside the reduction in LV function (Pacher, et al., 2002). Increased PARP-1 activity is maladaptive in the setting of $\mathrm{HF}$, as it leads to a reduction in the NAD ${ }^{+} / \mathrm{NADH}$ ratio by reducing the $N A D^{+}$pool, which reduces ATP production from pathways that require $N A D^{+}$ as a substrate (Pillai, et al., 2005). PARP-1 inhibition with an experiment inhibitor L-2286 has since been shown to prevent cardiac remodeling, LV systolic dysfunction, and delay progression to $\mathrm{HF}$, in rats with spontaneous hypertension (Bartha, et al., 2009). The deleterious changes in mitochondrial structure and function in $\mathrm{HF}$ are also due to the observed shifts in cardiac metabolism themselves. The reduced level of FA oxidation causes FA build up within the mitochondria, with lipid peroxide formation, whilst the decrease in glucose oxidation results in a build-up of lactate and hydrogen ions within the cell which alters cellular pH (Fillmore \& Lopaschuk, 2013; Munzel, et al., 2015). The resulting oxidative stress and disturbances in cellular $\mathrm{pH}$ directly damage both the mitochondrial membrane and important mitochondrial proteins (Dai, et al., 2012). As such, targeting the metabolic changes of HF may also prevent the downstream perturbations of mitochondrial biogenesis, function and energy transfer, as well as improving ATP generation.

\section{Metabolic Modulators: Promising Therapeutic Agents}

Over the last decade, metabolic modulation for the treatment and management of HF has garnered increasing attention, primarily due to the rather slow-paced development of other novel pharmacotherapeutic agents. The debate as to whether the decrease in FA oxidation during $\mathrm{HF}$ is protective or maladaptive has also been central to the development and use of metabolic modulators. It is more or less believed that inhibiting FA metabolism in parallel to 
enhancing glucose metabolism may be more beneficial (Doehner, et al., 2014). Such conclusions draw from evidence demonstrating that FA use is associated with an increase in ROS, which contributes to cardiac damage (Schonfeld \& Wojtczak, 2007). Furthermore, in the presence of low oxygen levels, FA metabolism is a less efficient method for ATP production. Taking these considerations into account, many metabolic therapies focus on inhibiting FA metabolism and increasing glucose metabolism.

Discussed below are several categories of metabolic modulating therapies, including 1) CPT1 inhibitors, 2) partial FA oxidation inhibitors, 3) malonyl-CoA decarboxylase inhibitors, 4) increased FA utilization, 5) increased glucose utilization, 6) AMPK activators, and 7) mitochondrial-targeted antioxidants. The CPT1 inhibitor perhexiline and partial FA inhibitors trimetazidine and ranolazine, are also indicated for clinical use in the treatment of refractory angina. Table 1 also provides a summary of metabolic modulators that are currently under investigation in clinical trials, withdrawn from clinical use, or for which there is pre-clinical data only.

\subsection{Carnitine palmitoyltransferase 1 (CPT1) inhibition}

CPT1 is an essential enzyme in FA metabolism, being necessary for the uptake of long chain FA's into the mitochondria. CPT1 inhibition, perhaps one of the most well-established and investigated forms of metabolic modulation, reduces long chain FA uptake and reciprocally increases carbohydrate oxidation via activation of PDH (Chong, et al., 2016). However, a recent metabolomics and proteomics study by Yin and colleagues, showed that perhexiline also donates protons within mitochondria to alter the redox environment, and increases lactate and amino acid uptake, which rebalances flux through the TCA cycle and increases 
NADH concentrations improving cellular energetics (Yin, Dwyer et al., 2013). By reducing mitochondrial FA levels it also potentially reduces mitochondrial toxicity due to lipid peroxides. Several agents exist which inhibit CPT1, including: etomoxir, oxfenicine, perhexiline and ranolazine (Revenco \& Morgan, 2009). Amiodarone (and the closely-related Dronedarone), a commonly used anti-arrhythmic drug, also possesses CPT1 inhibitorproperties (Kennedy, et al., 1996). Although less potent than perhexiline, given the high use of this drug in clinical practice for prophylaxis against malignant ventricular tachyarrhythmias (common following $\mathrm{AMI}$ ) and $\mathrm{AF}$, these ancillary effects may be important in both the beneficial effects and side effects of this class (Kennedy, et al., 1996). CPT1 inhibitors exert minimal haemodynamic effects, a clear benefit in comparison to many commonly used anti-anginals, avoiding symptomatic hypotension. In a small trial of patients with severe congestive HF, amiodarone therapy increased LVEF (19 $\pm 7 \%$ to $29 \pm 15 \%$; $\mathrm{P}<0.01)$, increased exercise tolerance and reduced the presence of non-sustained ventricular tachycardia ( $P=0.06$; Hamer, et al., 1989). These effects may be linked to CPT1 inhibition, but could also be due to restoration of sinus rhythm from AF. The efficacy of amiodarone treatment in reducing ventricular arrhythmias in $\mathrm{HF}$ patients has been established in multiple large-scale clinical trials (Neri, et al., 1987; Nicklas, et al., 1991).

A side effect of this class of drugs however, is the potential for phospholipidosis in various tissues (Ashrafian, Horowitz, et al., 2007). Liver lipidosis causing hepatotoxicity (Le Gall, et al., 1980) and neural lipidosis (in Schwann cells) causing neurotoxicity (Meier, et al., 1986) have been identified following perhexiline treatment, whilst systemic (Mazue, et al., 1984) and ocular lipidosis (Bockhardt, et al., 1978) have been observed with amiodarone. There is also the potential for hypoglycemia, which is a class-wide effect, due to the increase in 
plasma glucose uptake. Moreover, in a retrospective analysis of the COMET trial, treatment with amiodarone in HF patients was associated with an increased risk of death from circulatory failure, independent of NYHA functional class, which may be due to the development of AV block in patients with a LVEF <30\% (Torp-Pedersen, et al., 2007). Similar concerns have arisen for the use of dronedarone in HF, as there was an increase in mortality in patients with severe HF in the treatment arm compared to the placebo group (Kober, et al., 2008).

Etomoxir is an irreversible inhibitor of CPT1 (Horowitz, et al., 2010). In a rat ascending aortic constriction model of HF, etomoxir treatment for 12 weeks increased LV maximal developed pressure and contractile performance, and reduced LV wall stress (Turcani \& Rupp, 1997). Another study by Turcani and Rupp showed, using the same rat pressure overload HF model, that etomoxir treatment for 6 weeks enhanced LV function and prevented dilatation of the left ventricle (Turcani \& Rupp, 1999). A first-in-human study in $10 \mathrm{HF}$ patients confirmed these beneficial effects in the myocardium (Schmidt-Schweda \& Holubarsch, 2000). Treated patients showed an increase in EF $(21.5 \pm 2.6 \%$ to $27.0 \pm 2.3 \% ; \mathrm{P}<0.01)$ and CO following exercise (from $9.7 \pm 1.3$ L. $\mathrm{min}^{-1}$ to $13.4 \pm 1.5$ L. $\mathrm{min}^{-1} ; \mathrm{P}<0.01$ ). Unfortunately, clinical investigations into etomoxir therapy have largely ceased. This is due to the outcome of a trial of 260 patients with moderate HF, in which etomoxir therapy led to the development of abnormally high levels of liver transaminases in some patients and established hepatotoxicity in others (Holubarsch, et al., 2007). Therefore, investigations into the safety of this drug are necessary before commencing new clinical trials. 
Oxfenicine is an effective irreversible CPT1 inhibitor that was originally developed for use in patients with chronic stable angina (Revenco \& Morgan, 2009). In a canine coronary artery occlusion HF model, oxfenicine therapy reduced FA accumulation with a concomitant reduction in infarct size ( $72 \pm 2 \%$ vs $96 \pm 3 \%$; $\mathrm{P}<0.05$; Vik-Mo, et al., 1986). A study by Kennedy and colleagues also revealed that oxfenicine attenuated the rise in LVEDP following low-flow ischemia in a rat HF model (Kennedy, et al., 2000). Both of these studies highlight the beneficial effects of oxfenicine-induced FA oxidation inhibition within the myocardium under ischemic conditions. Lionetti and colleagues (2005) also demonstrated, in a canine pacing-induced HF model, that oxfenicine treatment reduced LV dilatation and hemodynamic alternations (Lionetti, et al., 2005). Furthermore, oxfenicine prevented the significant LV wall thinning observed in the placebo group, and delayed progression towards end-stage HF. To date, there are no large randomized clinical trials looking at the use of oxfenicine in HF patients, and this is perhaps due to the finding by Wang and colleagues that identified increases in LV internal resistance and impedance in the LV outflow tract, which worsened LV contractile function in oxfenicine-treated diabetic cardiomyopathic rat hearts, and increased plasma free FA toxicity (Wang, et al., 2013).

Perhexiline is a potent and reversible inhibitor of CPT1, originally used to treat angina in the 1970s (Ashrafian, Horowitz et al., 2007). The anti-anginal properties of perhexiline have been well-documented in early clinical trials (Cole, et al., 1990; Horowitz, et al., 1986) as well as its superior efficacy compared to propranolol (Armstrong, 1973). Such trials led to an increase in the use of perhexiline as an anti-ischemic agent up until the 1980s, when a range of adverse effects with perhexiline treatment became apparent, spanning from lethargy and nausea to severe neuro- and hepatotoxicity (Shah, et al., 1982). It was later 
established that perhexiline toxicity is due to prolonged exposure to high plasma levels, and was mainly seen in 'slow hydroxylators' (due to polymorphic variation of the P450 2D6 [CYP2D6] enzyme; Morgan, et al., 1984). With this clearer understanding of perhexiline pharmacokinetics and pharmacodynamics, it was identified that toxicity could be avoided by maintaining perhexiline plasma levels between 0.15 and $0.60 \mu \mathrm{g} / \mathrm{mL}$ (Horowitz, et al., 1986). Perhexiline also inhibits the cardiac isoform of CPT1 at a lower plasma concentration than the liver isoform, which allows for use of a lower dose to minimize adverse effects (Kennedy, et al., 1996). Dose-titration for perhexiline is also necessitated by the potential for metabolic drug-drug interactions and ultra-rapid metabolism in some patients (Davies, et al., 2004).

Both experimental and clinical investigations into the use of perhexiline as a therapeutic agent have since continued, employing close monitoring of plasma levels, and in a recent audit of 170 patients who had been on a perhexiline treatment regimen for up to 50 months, there were no signs of hepatotoxicity (Phuong, et al., 2016). In an open-chest canine model, perhexiline treatment was associated with an increase in LV mechanical efficiency, increased coronary blood flow, and a reduction in myocardial oxygen consumption, all of which were not achieved with GTN infusion alone (Ono, et al., 1982). A recent study by Gehmlich and colleagues revealed that perhexiline partially improved markers of LV hypertrophy following a 6 week intervention in mice with $\mathrm{HCM}$, and was accompanied by a reduction in FA $\beta$-oxidation and an increase in glucose utilization (Gehmlich, et al., 2015). Yin and colleagues also identified a potentiation of glucose oxidation with perhexiline therapy, via an increase in PDH dephosphorylation (signifying an increase in PDH activity), in mice fed perhexiline for 4 weeks (Yin, Dwyer et al., 2013). 
Perhexiline treatment also attenuated cardiac dysfunction caused by energy depletion and oxidative stress in mice with induced irreversible HF (Stapel, et al., 2016).

Translational trials in humans have also shown beneficial effects. Unger and co-workers demonstrated in a study of elderly patients with inoperable aortic stenosis, that perhexiline therapy provided symptomatic relief, improving NYHA functional class (Unger, et al., 1997). In a double-blind randomized placebo controlled trial by our group, perhexiline treatment in patients with HFrEF significantly improved EF $(24 \%$ to $34 \%, \mathrm{P}<0.001)$ and peak exercise oxygen consumption (Peak VO $216.1 \pm 0.6$ vs $\left.18.8 \pm 1.1 \mathrm{ml} \cdot \mathrm{kg}^{-1} \cdot \mathrm{min}^{-1}, \mathrm{P}<0.001\right)$ (Lee, et al., 2005). In another clinical study by our group, perhexiline improved myocardial energetic status (improved PCr/ATP ratio; from 1.3 to $1.7 ; \mathrm{P}=0.03)$, NYHA class $(\mathrm{P}<0.001$ ), and corrected diastolic dysfunction in symptomatic non-obstructive HCM patients (Abozguia, et al., 2010).

In a recent randomized controlled trial, short-term treatment with perhexiline in patients with non-ischemic HFrEF caused a 30\% increase in PCr/ATP ratio (from 1.2 to $1.5 ; \mathrm{P}<0.001$ ) and an improvement in NYHA status (Beadle, et al., 2015). However, this study found no change in cardiac substrate utilization despite these clear beneficial effects on energetic status, suggesting an alternative mechanism of action rather than CPT1 inhibition, at least with short term administration. Similarly, in the isolated rat heart models by Kennedy et al (2000) and Unger et al (2005), perhexiline perfusion did not alter FA oxidation or CPT1 activity (Kennedy, et al., 2000; Unger, et al., 2005), despite markedly increasing LV mechanical efficiency. 
Additional effects of perhexiline include blockade of the NAD(P)H oxidase 2 (Nox2) complex, conveying beneficial anti-inflammatory effects (Gatto, et al., 2013; Kennedy, et al., 2006; Liberts, et al., 2007), and reduced expression of TXNIP (Ngo, et al., 2011). Moreover, a recent study reports that perhexiline activates Krüppel-like factor 14 (KLF14), which regulates lipid metabolism, reducing atherosclerotic lesion development in a mouse model (Guo, et al., 2015). However, perhexiline has also been shown to inhibit the mammalian target of rapamycin complex 1 (mTORC1; Balgi, et al., 2009), an effect which is shared by amiodarone. The mTOR-signaling pathway relays signals of adequate energy supplies to inhibit cardiomyocyte autophagy, which is over-activated (due to AMPK activation, which inhibits mTOR; Matsui, et al., 2007) and maladaptive in the hypertrophic failing heart (De Meyer, et al., 2010). This ancillary property of perhexiline is likely to affect the careful balance of cardiac autophagy and therefore disease progression and prognosis in $\mathrm{HF}$, however further investigation is needed to test this.

\subsection{Partial fatty acid oxidation inhibition}

Partial FA oxidation inhibitors inhibit FA metabolism via mechanisms other than CPT1 inhibition and therefore do not completely block the uptake and use of FAs (Chong, et al., 2016). Well-investigated agents include trimetazidine and ranolazine, both of which have been established for use as prophylactic anti-anginal agents (Lee, et al., 2004). Trimetazidine works by inhibiting the LC 3-KAT enzyme of the $\beta$-oxidation pathway (Kantor, et al., 2000), but also has weak inhibitory effects on CPT1 (Lee, et al., 2004). An experimental study in mice with diabetic cardiomyopathy demonstrated improvements in both systolic and diastolic function following trimetazidine treatment, as well as a reduction in ROS and improvement in cardiac energetic status (Li, et al., 2010). Clinical studies in man have also 
supported the beneficial effects of trimetazidine. Fragasso and colleagues observed a significant improvement in NYHA functional class in patients with $\mathrm{HF}$, an increase in EF ( $36 \pm 7 \%$ vs $43 \pm 10 \% ; P=0.002$ ), and a decrease in LV end-systolic volume (98 $\pm 1.36 \mathrm{ml}$ vs $81 \pm$ $27 \mathrm{ml} ; \mathrm{P}=0.04$ ) when compared to the untreated group (Fragasso, et al., 2006). Moreover, in a clinical study by Tuunanen et al (2008) involving patients with idiopathic DCM and HFrEF, trimetazidine increased EF (from $30.9 \pm 8.5 \%$ to $34.8 \pm 12 \%$; $\mathrm{P}=0.027$ ) with observed increases in cardiac glucose oxidation (Tuunanen, et al., 2008). A meta-analysis by Zhang et al (2012) confirmed these therapeutic effects by assessing data collected from 16 RCTs involving over 800 chronic HF patients (Zhang, et al., 2012). They found that the use of trimetazidine reduced hospitalization, improved symptoms and NYHA functional class, increased EF, and ameliorated LV remodeling. In patients with coronary 'slow flow', trimetazidine also significantly improved LV diastolic function (Suner \& Cetin, 2016). Although adverse effects with trimetazidine are rare, potential side effects include Parkinsonian symptoms (tremor, bradykinesia, and hypertonia) and gait disorders (coupled with disequilibrium), however the mechanism for these symptoms has not yet been defined (Marti Masso, et al., 2005).

Ranolazine is a similar compound to trimetazidine, which has partial LC 3-KAT inhibiting properties and can stimulate glucose oxidation (although there is controversy regarding the significance of these effects at therapeutic concentrations; Beadle \& Frenneaux, 2010). Additionally, it is an inhibitor of the slow inward sodium channel that is activated during ischemia and in HF, resulting in an increase in intracellular sodium and thereby, via the sodium-calcium exchanger, leads to increased intracellular calcium. This results in action potential prolongation and improved diastolic filling. However, it is important to note that 
increased calcium-signaling within the myocardium has a high ATP-cost in the failing heart. Rarely, ranolazine (as a cationic amphiphilic drug) may induce renal phospholipidosis in some patients (Scheurle, et al., 2014). The drug has significant anti-anginal effects such as increasing time to angina, reducing the number of weekly anginal episode and increasing exercise duration (Chaitman, et al., 2004). In a recent study by Zou and colleagues (2016) ranolazine restored mitochondrial function, prevented oxidative stress, and inhibited apoptosis in a rat model of atrial fibrillation (Zou, et al., 2016). In another recent study, rats were subjected to chronic ischemic HF by left anterior descending artery ligation (Feng, et al., 2016). Ranolazine treatment in these rats attenuated brain natriuretic peptide (BNP) levels and improved LV function. Furthermore, in a study of rats fed a high salt diet to induce hypertension, ranolazine therapy reduced oxidative stress and attenuated diastolic dysfunction (De Angelis, et al., 2016). Importantly, a 30-minute ranolazine infusion in patients with HFpEF reduced LVEDP in the RALI-DHF study (Maier, et al., 2013). In another study by Murray and Colombo, up to $70 \%$ of patients with HFrEF showed an improvement in EF when treated with ranolazine, compared to no improvement in the noradrenaline treatment arm (Murray \& Colombo, 2014).

\subsection{Malonyl-CoA decarboxylase inhibitors}

The MCD enzyme converts malonyl-CoA into acetyl CoA in the cytosol. MCD inhibition increases malonyl-CoA which is a natural inhibitor of the CPT1 enzyme and therefore reduces long chain free FA transport into the mitochondria (Fillmore \& Lopaschuk, 2013). MCD inhibition also increases cardiac carbohydrate oxidation by increasing PDH activity (due to reduced allosteric inhibition from acetyl-CoA generated from FA oxidation and lower cytosolic citrate levels, i.e. the Randle cycle) and increases insulin sensitivity (Cheng, et al., 
2006). In an experimental study by $\mathrm{Wu}$ and colleagues, MCD inhibition was achieved via MCD myocardial gene silencing in rats. Cardiac contractile function measured sixteen weeks after the induction of myocardial infarction demonstrated attenuation in post-MI dysfunction in the treatment group when compared to the control group, with an $8 \%$ decrease in EF vs. a 16\% decrease in EF, respectively (Wu, et al., 2014). High energy phosphate (PCr and ATP) levels were also increased in the left ventricle of the group with MCD gene silencing, without lipid toxicity. In a porcine ischemic HF model, the use of novel MCD inhibitors significantly increased glucose oxidation which was accompanied by significant increases in cardiac performance (Dyck, et al., 2004). In a mouse coronary artery ligation induced HF model, MCD knockout mice had a 31\% higher EF in comparison to their wild-type litter mates and a greater rate of ATP production (Masoud, et al., 2014). To date there are no clinical studies assessing the use of MCD inhibition in humans, however the experimental evidence in animal models of ischemic heart disease and HF have shown promise, and in theory, this method of indirect CPT1 inhibition should provide similar beneficial effects to direct CPT1 inhibition. MCD inhibition therefore provides a novel and useful mechanism by which cardiac metabolism can be improved and requires further clinical investigation to determine whether these beneficial effects translate to HF patients.

\subsection{Increased fatty acid utilization}

Despite the success of FA metabolic inhibition in HF to increase glucose oxidation, some groups have instead focused on increasing FA utilization (oxidation). Kolwicz and colleagues subjected mice with cardiac-specific deletion of ACC (the enzyme that produces malonyl CoA from acetyl CoA, and which is a target of AMPK), to TAC to induce HF (Kolwicz, et al., 2012). They reported a preservation of myocardial energetics and a reduction in both 
cardiac hypertrophy and fibrosis following TAC in the knock-in mice compared to wild-type mice. Furthermore, analysis of isolated hearts from these ACC2-TAC mice revealed that glycolytic activity was reduced with no indication of changes in glucose oxidation, thereby suggesting improved coupling of glycolysis and glucose oxidation. Chess and colleagues investigated the effects of a high-fat diet on mice subjected to TAC (Chess, et al., 2009). The authors reported that the high-fat diet did not worsen cardiac hypertrophy or LV enlargement but did prevent the decline in the activity of mitochondrial oxidative enzymes when compared to TAC mice on a low-fat diet.

Increasing FA metabolism via activation of FA transcription regulators, such as PPAR $\alpha$ via the use of fibrates, has also been used in an attempt to ameliorate HF (Sarma, et al., 2012). PPARy agonists (such as thiazolidinediones) however, are contraindicated in diabetic patients with symptoms of advance $\mathrm{HF}$, due to the increased incidence of worsening oedema in these patients in both monotherapy and combination therapy trials for glycaemic control (Nesto, et al., 2003). The PPAR $\alpha$ activator GW7647 prevented the decline in EF and increased cardiac FA $\beta$-oxidation in rabbits with volume-overload hypertrophy (Lam, et al., 2015). The PPAR $\alpha$ agonist fenofibrate, has also been shown to reduce serum BNP levels and mitochondrial ROS production in rats with isoproterenol-induced HF (Li, et al., 2015). In canines with LV pacing-induced HF, chronic treatment with fenofibrate prevented the reduction in FA oxidation observed in the untreated group whilst also causing modest improvements in cardiac function (Labinskyy, et al., 2007). Fenofibrate treatment has also been found to have beneficial effects on endothelial function in patients with advanced systolic HF (Yin, Chen et al., 2013) and symptomatic chronic HF (Huang, et al., 2009). Gemfibrozil has been reported to attenuate cardiac hypertrophy and oxidative stress in rats 
subjected to abdominal aortic constriction (Singh, et al., 2015). Selective PPAR $\beta / \delta$ agonists have also been shown to have beneficial cytoprotective effects in rat cardiomyocytes subjected to oxidative stress (Barlaka, et al., 2015). To date there are no clinical trials that have studied PPAR a agonists as specific metabolic therapies in HF. Activators of the PPAR regulator SIRT-1 however, such as resveratrol (which also activates AMPK by inhibiting ATP synthase; Price, et al., 2012), have been tested in the pre-clinical setting and were found to reduce oxidative stress in failing hamster hearts (Tanno, et al., 2010) and improve cardiac function in rats subjected to arterial ligation (Gu, et al., 2014). It has been identified however, that overexpression of SIRT-1 can impair diastolic function and in fact may cause DCM (Kawashima, et al., 2011). These studies suggest that increasing FA levels and metabolism in HF may help to preserve mitochondrial oxidative capacity.

\subsection{Glucose-Insulin-Potassium (GIK) infusion}

Infusion of Glucose-Insulin-Potassium (GIK) increases plasma glucose and cellular glucose uptake, whilst reducing lipolysis and lowering plasma free FAs, which by the Randle cycle, increases carbohydrate oxidation (Beadle \& Frenneaux, 2010). Insulin also activates the phosphatidylinositol 3-kinase (PI3K)-Akt-eNOS pathway, increasing myocardial NO (which is deficient in HF) and has known cytoprotective effects (Yao, et al., 2014). Through these mechanisms myocardial oxygen consumption and ROS accumulation are decreased, improving overall myocardial energetics (Cave, et al., 2000). Our group has also shown that GIK therapy in addition to standard myocardial protection, in $>200$ patients undergoing cardiac surgery for critical aortic stenosis with significant LV hypertrophy, was associated with a lower incidence of low cardiac output syndrome (with a reduction in inotrope use in the early postoperative period) compared to the control arm (Howell, et al., 2011). 
Mechanistically, we showed that GIK resulted in increased AMPK and Akt phosphorylation, and post-translational O-linked $\beta$-N-acetylglucosamination of cytoprotective myocardial proteins in LV biopsies from treated patients. A recent study by Worthley et al. (2007), demonstrated a mechanistic basis for beneficial effects with intensive insulin administration in 76 hyperglycemic diabetic patients following acute coronary syndromes (ACS). The authors showed reduced NO bioavailability in these patients (due to consumption of NO by superoxide), which led to impaired platelet responsiveness to its anti-aggregatory effects, and that this was reversed with the intervention (Worthley, et al., 2007). In a meta-analysis conducted by Fath-Ordoubadi and Beatt (1997), 9 randomized trials in which GIK therapy was used for the treatment of acute myocardial infarction (AMI) were collated and reviewed (Fath-Ordoubadi \& Beatt, 1997). This meta-analysis revealed that in-hospital mortality was reduced following GIK therapy in these patients, when compared to placebo ( $16 \%$ vs $21 \%$; $\mathrm{P}=0.004)$. However, in a more recent meta-analysis, no difference in mortality between the treated and untreated groups was found (Mamas, et al., 2010). In addition, the large-scale clinical trial, CREATE-ECLA, involving 20,201 patients with acute ST-segment elevation myocardial infarction (STEMI), revealed that GIK infusion had no significant effects on the rate of cardiac arrest, cardiogenic shock or mortality (Mehta, et al., 2005). This lack of effect on mortality was consistent between patients with and without HF as well as with and without diabetes. It appears therefore, that GIK may be most beneficial in the diabetic cohort of patients with ACS, however this may not translate to a reduction in mortality in excess of contemporary therapies for ACS.

Recent clinical investigations have been conducted to specifically assess the use of GIK in the chronic HF setting (Kalay, et al., 2008; Nicolas-Robin, et al., 2008). Kalay and colleagues 
(2008) treated 33 patients with HFrEF due to ischemic cardiomyopathy with GIK and analysed cardiac function and BNP levels. The authors observed an improvement in EF (from $29.2 \pm 10.3 \%$ to $40.8 \pm 10.8 \% ; \mathrm{P}=0.001$ ) following 1 week in the treatment group, and a significantly lower plasma BNP compared to the placebo group. Similarly, Nicolas-Robin and colleagues (2008) investigated the effects of GIK infusion in severe HF following brain death. They found that GIK treatment was effective at increasing EF ( $37 \pm 8$ vs $21 \pm 6 \%, P<0.0001)$, without significantly altering blood pressure or heart rate.

\subsection{GLP-1 Analogues}

Glucagon-like peptide-1 (GLP-1) analogues, such as Exenatide, are commonly used for the treatment of type 2 diabetes mellitus for glycaemic control, and have also been shown to improve $\beta$-cell function and reduce body weight in these patients (Madsbad, et al., 2004; Zander, et al., 2002). Previous studies have demonstrated that GLP-1 infusion has beneficial effects on cardiovascular function in conjunction with its anti-diabetic properties by improving EF, NYHA functional status and peak exercise oxygen consumption (Sokos, et al., 2006; Wroge \& Williams, 2016). GLP-1 analogue infusion following AMI has also been shown to have cardioprotective benefits, likely from activation of the PI3K-Akt pathway and through increasing cytosolic CAMP, which inhibit the mitochondrial permeability transition pore (mPTP), and increase myocardial expression of PPAR- $\beta / \delta$, nuclear factor related factor 2 (Nrf-2), and haemoxygenase-1 (HO-1; Giblett, et al., 2016). Liraglutide therapy has also been shown to increase plasma ANP levels due to atrial GLP-1 receptor activation, which has potent natriuretic and antihypertensive effects via increased vascular cGMP (Kim, et al., 2013). In both rat and mouse models of HF, exenatide treatment delayed the progression towards HF and increased survival rates following AMI (Wroge \& Williams, 2016). 
Furthermore, Nathanson and colleagues demonstrated that intravenous infusion of Exenatide, in patients with type 2 diabetes and $\mathrm{HF}$, increased cardiac index $(\mathrm{Cl})$ and reduced PCWP (Nathanson, et al., 2012).

\subsection{Dichloroacetate (DCA)}

The pyruvate analogue DCA is an inhibitor of PDH kinase, which phosphorylates and inhibits PDH. Therefore DCA increases PDH activity and carbohydrate oxidation (Fillmore \& Lopaschuk, 2013). DCA is an effective treatment for lactic acidosis by directing pyruvate conversion away from lactate and towards acetyl-CoA. As PDH activity is reduced in HF, DCA has been suggested as a potential treatment strategy (Lewis, et al., 1998). In a high salt dietinduced HF model in rats, DCA treatment was found to increase glucose uptake, improve cardiac function by reducing progression to $\mathrm{HF}$, and improve overall survival (Kato, et al., 2010). Furthermore, in a set of in vitro cardiomyocyte studies, DCA was shown by the same group to reduce oxidative stress and prevent cell death (Kato, et al., 2010). DCA treatment also enhanced mitochondrial metabolism and suppressed apoptotic cell death in a neonatal mouse model of hypoxic ischemia (Sun, et al., 2016). In a clinical study by Bersin et al (1994) of patients with chronic HF, a 30-minute infusion of DCA increased LV function (increase in stroke volume: $+5.3 \mathrm{ml} /$ beat; $\mathrm{P}<0.02$; and LV stroke work: $+1.8 \mathrm{~g} / \mathrm{m}^{2} /$ beat; $\mathrm{P}<0.02$ ) whilst also reducing myocardial oxygen consumption (from 19.3 to $16.3 \mathrm{ml} / \mathrm{min} ; \mathrm{P}=0.06$ ). In addition, LV mechanical efficiency was improved (from $15.2 \%$ to $20.6 \%$; $P=0.03$; Bersin, et al., 1994). Importantly however, long term use of DCA may result in peripheral neuropathy and this may limit its potential therapeutic applications (Calcutt, et al., 2009). 


\subsection{AMPK activators}

As a key regulator of cellular energy homeostasis, pharmacological activation of AMPK in the setting of metabolic syndromes such as HF has been suggested. In particular, indirect activators of AMPK such as 5'-aminoimidazole-4-carboxyamide-ribonucleoside (AICAR) and the biguanide metformin have shown promise (Kim \& Dyck, 2015). As stated, activated AMPK increases insulin-independent glucose uptake via GLUTs 1 \& 4, increases gluconeogenesis and glycolysis (via SIRT1-PGC1 signaling), increases lipolysis and FA synthesis, and increases free FA uptake and oxidation (by reducing malonyl CoA levels; (Zaha \& Young, 2012). AICAR treatment reduced LV hypertrophy in rat cardiomyocytes (Chan, et al., 2004) and in pressure-overload mice (Li, et al., 2014). Oxidative stress-induced apoptosis and progression of HF were attenuated by metformin therapy in a canine model of rapid pacing-induced HF (Sasaki, et al., 2009). The authors observed a reduction in LVEDP, attenuated oxidative stress, and slower progression of HF in the treatment arm when compared to controls. In mice subjected to left coronary artery occlusion, metformin therapy improved survival by $47 \%$, preserved LV structure and EF, and improved mitochondrial respiration and ATP production (Gundewar, et al., 2009). In a non-diabetic post-infarct rat model of $\mathrm{HF}$, animals treated with metformin had significantly smaller infarct sizes, reduced LV cavity dilation, and a preserved EF when compared to untreated rats (Yin, et al., 2011). In addition, Xiao and colleagues found that metformin inhibited cardiac fibrosis in TAC mice (Xiao, et al., 2010). A retrospective analysis by Eurich et al (2005) of patients with HF and type 2 diabetes, demonstrated lower morbidity and mortality following metformin treatment (Eurich, et al., 2005). However, a randomized controlled trial by the same group in 2009 was abandoned due to significant issues with patient recruitment, stemming from the very high rates of metformin prescribing in clinical practice, 
including those patients in whom metformin is contraindicated (Eurich, et al., 2009). However, others have shown that metformin is quite safe in advanced HFrEF (Shah, et al., 2010), and further clinical studies are warranted.

\subsection{Mitochondrial-targeted antioxidants}

Coenzyme Q10 (CoQ10), also known as ubiquinone, plays an essential role in oxidative phosphorylation as it forms part of the ETC within the mitochondria. Although an endogenous substance, CoQ10 can also be given as a non-prescription nutritional supplement, and therefore the use of CoQ10 as a therapeutic treatment for cardiovascular disease has been investigated by a broad range of clinical studies (Sharma, Fonarow et al., 2016). Levels of CoQ10 tend to decline with age, and deficiency has been associated with diseases such as HF. In fact, a close positive correlation between HF severity and severity of CoQ10 deficiency has been identified (Oleck \& Ventura, 2016). It has been proposed that the antioxidant and free radical scavenging properties of CoQ10 are important in combatting harmful effects from the high ROS observed in HF patients (Sharma, Fonarow et al., 2016). Furthermore, the vital role of CoQ10 in oxidative phosphorylation suggests that ATP generation may be directly enhanced via CoQ10 supplementation (Oleck \& Ventura, 2016).

One of the first clinical trials of CoQ10 therapy in patients with HF was carried out in the 1980s (Langsjoen, et al., 1985). Langsjoen and colleagues (1985) demonstrated, in a study of 143 patients, an improvement in stroke volume and EF following CQ10 treatment over a 12week period. Further studies have confirmed these improvements in cardiac function in HF patients, but these have translated to only minimal improvements in mortality (Morisco, et 
al., 1994; Munkholm, et al., 1999). Many of these trials however, were underpowered to assess this end-point, and were performed at a time that coincided with the advent of ACEinhibitor and $\beta$-blocker therapies, which revolutionized HF treatment and drastically improved survival in their own right. A meta-analysis by Sanders and colleagues reviewed the data collected from 11 randomized trials dated between 1966 and 2005 (Sander, et al., 2006). They reported that isolated CoQ10 therapy caused a net $3.7 \%$ improvement in EF and an increase in $\mathrm{CO}$, thereby improving systolic function in chronic $\mathrm{HF}$, however the heterogeneity in 'standard treatment' over the course of these studies makes direct comparison difficult. The meta-analysis carried out by Fotino et al (2013), also demonstrated similar findings, reporting an increase in cardiac performance and improvement in NYHA functional class. However the effects on mortality still remain unclear (Fotino, et al., 2013). More recently, a randomized controlled trial (Q-SYMBIO), conducted with 420 patients with moderate to severe HF, has been completed (Mortensen, et al., 2014). Patients were given $100 \mathrm{mg}$ CoQ10 three times daily in addition to standard therapy for 2 years. The results of the study revealed an improvement in cardiovascular mortality (9\% vs $16 \%, P=0.026)$, and reduced hospital admissions for HF $(P=0.033)$ when compared to the placebo group. Furthermore, this study confirmed that long-term treatment with CoQ10 is safe for use in HF in the context of modern therapies, however larger contemporary RCTs assessing the efficacy of CoQ10 in HF are still necessary.

Most 'conventional' antioxidants that have been studied in clinical trials achieve low mitochondrial concentrations, which may limit their efficacy. However, a number of novel antioxidants have been developed that are selectively concentrated in the mitochondria because they are lipophilic and negatively charged (Munzel, et al., 2015). Most notable of 
these are MitoQ and SS31. Developed in the late 1990s, MitoQ consists of CoQ10 conjugated with the lipophilic compound triphenylphosphonium. This allows it to accumulate extensively and selectively within the mitochondria (Bayeva, et al., 2013). MitoQ therapy was found to protect cardiac function in a spontaneously hypertensive rat model of HF (Graham, et al., 2009) and to reduce mitochondrial oxidative stress and ROS levels in an anthracycline-induced model of cardiac failure (Chandran, et al., 2009). A limitation of MitoQ therapy and other triphenylphosphonium-conjugated antioxidants however, is that their uptake relies upon preservation of the mitochondrial membrane-potential, which may be altered in HF (Bayeva, et al., 2013).

SS31 is a tyrosine-containing Szeto-Schiller peptide which selectively accumulates within the mitochondria, and is unaffected by membrane potential (Bayeva, et al., 2013). Within the mitochondria, SS31 binds to cardiolipin and protects the structure and organization of respirasomes, facilitating electron transfer and promoting oxidative phosphorylation (Szeto, 2014). In a hypertensive mouse model of HF, SS31 treatment attenuated cardiac hypertrophy, cardiac fibrosis and diastolic dysfunction (Dai, et al., 2011). Furthermore, in a mouse TAC model, SS31 therapy ameliorated cardiac hypertrophy, cardiac fibrosis and systolic dysfunction and also abolished mitochondrial oxidative damage (Dai, et al., 2013).

Elamipretide is a tetrapeptide that crosses the outer mitochondrial membrane and, like SS31, associates with cardiolipin in the inner mitochondrial membrane, stabilizing it and facilitating the maintenance of respirasome organization (Szeto, 2014). A first-in-human RCT, involving 118 first-time anterior STEMI patients undergoing successful angioplasty, investigated the additive effect of Elamipretide (MTP-131) vs placebo on infarct size, as 
assessed by the creatine kinase myocardial band (CK-MB) area under the curve over $72 \mathrm{~h}$ (Gibson, et al., 2016). The drug was well tolerated, however the results did not reach significance compared to the placebo group. In a recent study using a canine microembolization model of $\mathrm{HF}$, elamipretide administered for 3 months was associated with higher LVEF and reduced plasma BNP when compared to placebo (Sabbah, et al., 2016). Furthermore, elamipretide increased mitochondrial membrane potential, rate of ATP synthesis, and reduced mitochondrial ROS generation. Phase 2 studies investigating the effects of Elamipretide in patients with HF are ongoing (NCT02788747; NCT02814097).

As previously stated, increased ROS in HF inhibits cytosolic CK activity and thereby impairs energy transfer from the mitochondria to the site of utilization in the cytosol (Rosca \& Hoppel, 2013). As such, increasing CK flux via the inhibition of superoxide generation by the xanthine oxidoreductase enzyme (an important source of mitochondrial ROS) has been suggested as a potential therapeutic strategy in HF (Gavin \& Struthers, 2005). A small and recent randomized trial, of 16 non-ischemic HFrEF patients, demonstrated increased myocardial CK flux following intravenous allopurinol therapy in parallel with increased cytosolic CK activity (Hirsch, et al., 2012).

\section{Conclusion}

Cardiac energetic impairment plays an important role in the pathophysiology of both HFrEF and HFpEF. Pharmacotherapeutic agents that reduce FA oxidation and increase glucose oxidation improve energy generation and show promise for the treatment of HF. Other agents that target mitochondrial oxidative stress are also being investigated. With this in mind, shifting the focus of new pharmacotherapies away from neurohormonal treatments 
and towards metabolic modulation may help us to re-energize our efforts to improve mortality and quality of life for sufferers of this malignant disease.

\section{Conflict of Interest Statement}

M.P.F. is the inventor of method of use patents for perhexiline in heart muscle diseases.

These patents are held by a company with whom he has no financial or other association. H.N., B.L.L., and M.M. have no conflicts to declare. 
Fig 1:

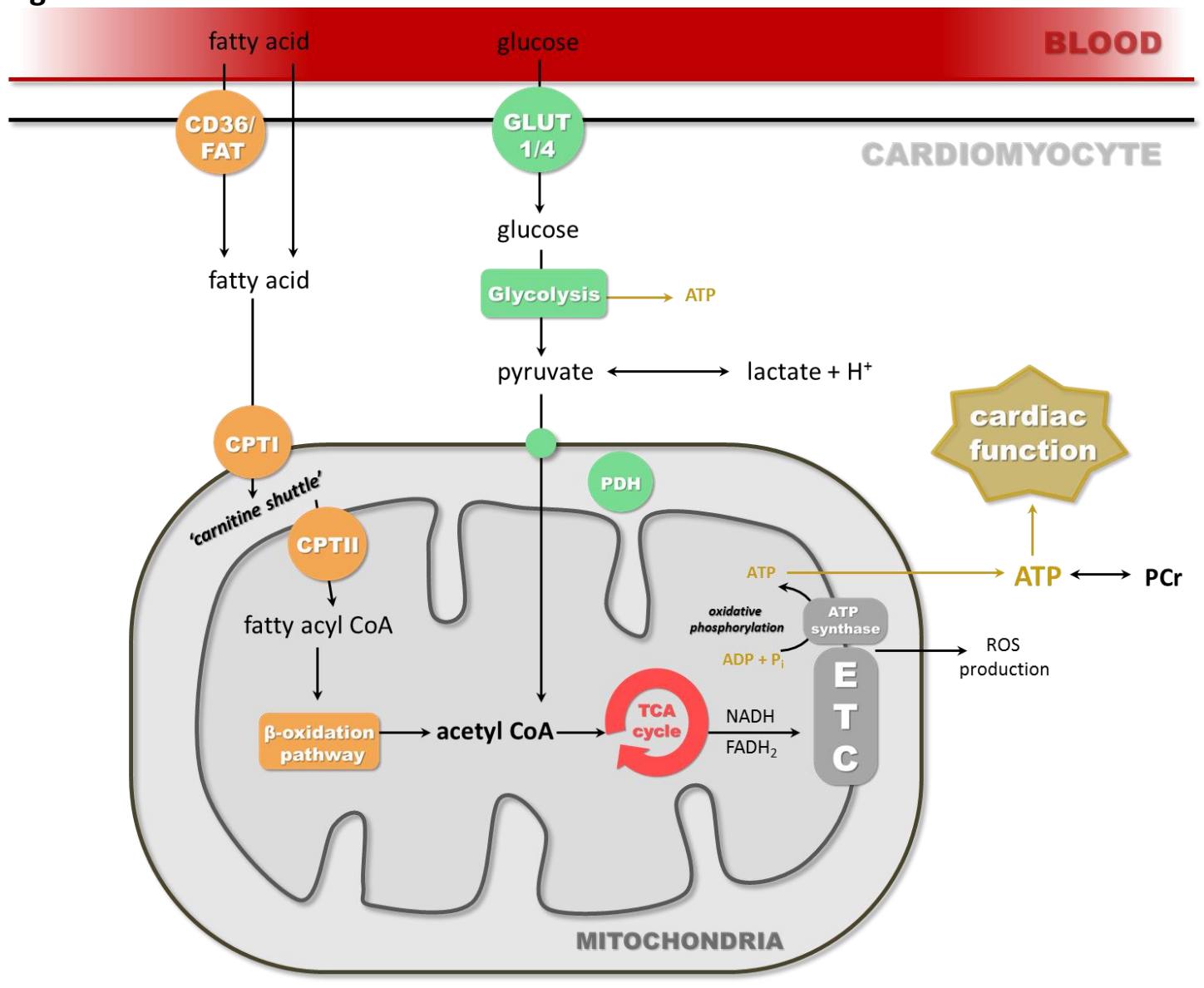

Fig 1: An Overview of Cardiac Metabolism in the Healthy Heart

Fatty acids and glucose are both key substrates of cardiac metabolism. Through various enzymatic pathways these substrates generate high levels of adenosine triphosphate (ATP) within the mitochondria of a heathy heart. ATP generation is essential in order to fuel continuous cardiac function.

ADP, adenosine diphosphate; ATP, adenosine triphosphate; CoA, coenzyme A; CPT, carnitine palmitoyltransferase; ETC, electron transport chain; FADH2, flavin adenine dinucleotide; FAT, fatty acid translocase; GLUT, glucose transporter; $\mathrm{H}+$, hydrogen ion; $\mathrm{PCr}$, phosphocreatine; $\mathrm{Pi}$, inorganic phosphate; $\mathrm{PDH}$, pyruvate dehydrogenase; $\mathrm{TCA}$, tricarboxylic acid; ROS, reactive oxygen species. 
Fig 2:

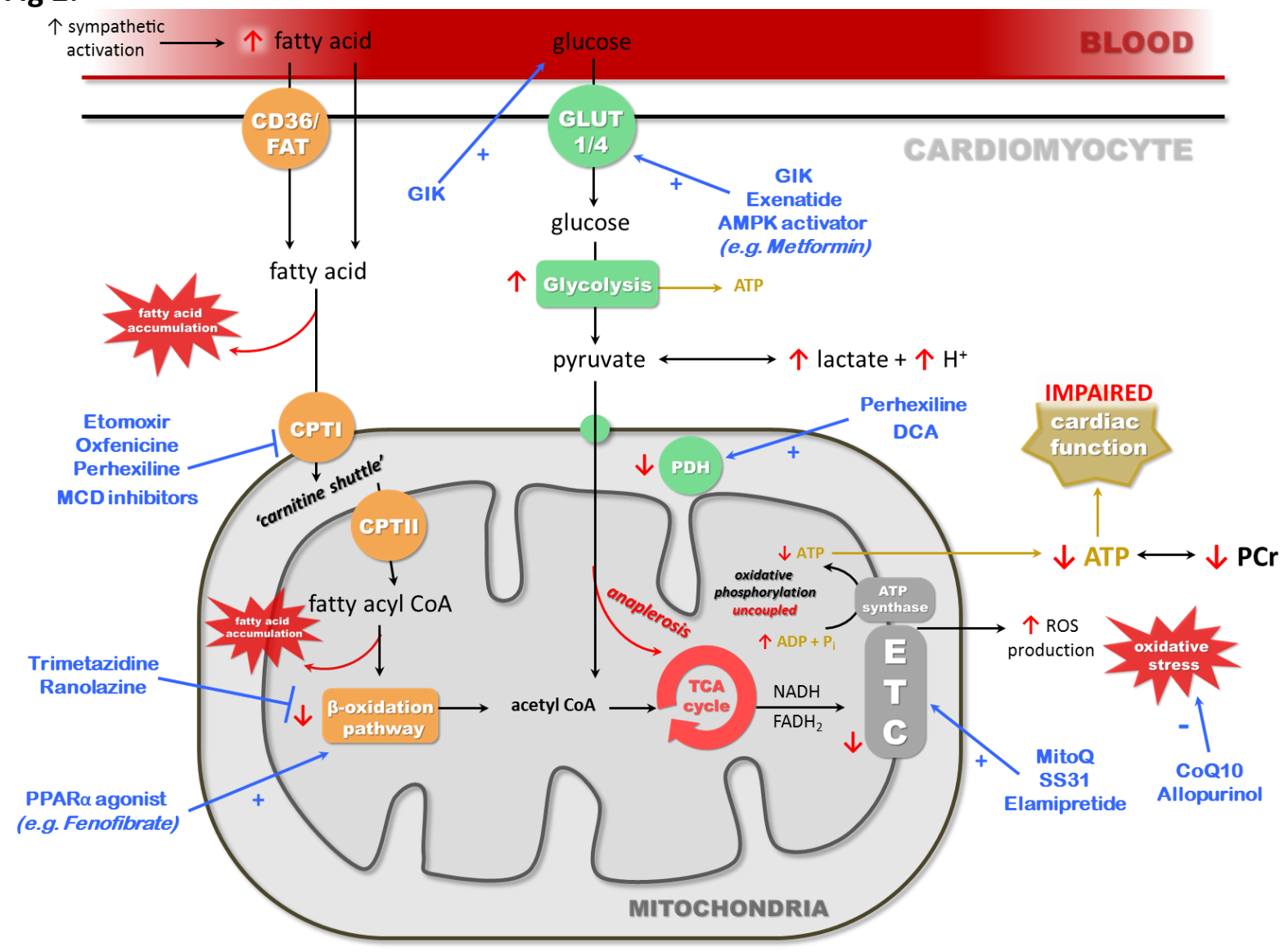

Fig 2: An Overview of Cardiac Metabolism in the Failing Heart and Targets of Metabolic Modulators

Severe disturbances in cardiac metabolism decrease adenosine triphosphate (ATP) production in heart failure, including decreased fatty acid (FA) and glucose oxidation, and high reactive oxygen species (ROS) levels. Many drugs that modulate cardiac metabolism have been identified and differ in their mechanisms to restore cardiac energetic production. ADP, adenosine diphosphate; ATP, adenosine triphosphate; CoA, coenzyme A; CoQ10, coenzyme Q10; CPT, carnitine palmitoyltransferase; DCA, dichloroacetate; ETC, electron transport chain; $\mathrm{FADH}_{2}$, flavin adenine dinucleotide; FAT, fatty acid translocase; GIK, Glucose-Insulin-Potassium; GLUT, glucose transporter; $\mathrm{H}^{+}$, hydrogen ion; $\mathrm{MCD}$, malonyl-CoA decarboxylase; $\mathrm{PCr}$, phosphocreatine; $\mathrm{P}_{\mathrm{i}}$, inorganic phosphate; $\mathrm{PDH}$, pyruvate dehydrogenase; TCA, tricarboxylic acid; ROS, reactive oxygen species. 
Table 1: Metabolic modulator clinical status

Key metabolic modulators that have been proposed for use as novel treatments for heart failure and their associated metabolic action and clinical status.

AMPK, adenosine monophosphate-activated protein kinase; ATP, adenosine triphosphate; BNP, brain natriuretic peptide; CPT1, carnitine palmitoyltransferase 1; ETC, electron transport chain; GLP-1, glucagon-like-peptide-1; HPAECs, human pulmonary artery endothelial cells; LC 3-KAT, long-chain 3-ketoacyl-CoA thiolase; LV, left ventricular; LVEF, left ventricular ejection fraction; NYHA, New York Heart Association; PBMCs, peripheral blood mononuclear cells; PCWP, pulmonary capillary wedge pressure; PDK, pyruvate dehydrogenase kinase; PPAR $\alpha$, peroxisome proliferator-activated receptor $\alpha$; ROS, reactive oxygen species; SIRT1, Sirtuin 1. 


\begin{tabular}{|c|c|c|c|c|c|c|}
\hline Metabolic agent & Drug class & $\begin{array}{l}\text { Key metabolic } \\
\text { mechanism }\end{array}$ & FDA status & $\begin{array}{c}\text { Stage of development as } \\
\text { metabolic modulator in HF }\end{array}$ & Key results & Key references \\
\hline Etomoxir & $\begin{array}{l}\text { Irreversible CPT1 } \\
\text { inhibitor }\end{array}$ & $\begin{array}{l}\text { Fatty acid oxidation } \\
\text { inhibition }\end{array}$ & \multicolumn{2}{|c|}{$\begin{array}{l}\text { Withdrawn from clinical use due to severe } \\
\text { hepatotoxicity }\end{array}$} & $\begin{array}{l}\text { Increase in LVEF and CO following } \\
\text { exercise vs placebo }(P<0.01)\end{array}$ & $\begin{array}{l}\text { Schmidt-Schweda and } \\
\text { Holubarsch, 2000, } \\
\text { Holubarsch et al., 2007 }\end{array}$ \\
\hline Oxfenicine & $\begin{array}{l}\text { Irreversible CPT1 } \\
\text { inhibitor }\end{array}$ & $\begin{array}{l}\text { Fatty acid oxidation } \\
\text { inhibition }\end{array}$ & \multicolumn{2}{|c|}{ Pre-clinical data only } & $\begin{array}{l}\text { Canine rapid pacing HF: } \\
\text { Reduction in LV dilatation and } \\
\text { hemodynamic alternations vs placebo } \\
(P<0.05)\end{array}$ & Lionetti et al., 2005 \\
\hline Amiodarone & $\begin{array}{l}\text { Class III anti- } \\
\text { arrhythmic; } \\
\text { CPT1 inhibitor }\end{array}$ & $\begin{array}{l}\text { Fatty acid oxidation } \\
\text { inhibition }\end{array}$ & $\begin{array}{l}\text { FDA approved } \\
\text { Ventricular } \\
\text { arrhythmias }\end{array}$ & Phase II & $\begin{array}{l}\text { Reduction in non-sustained ventricular } \\
\text { tachycardia }(\mathrm{P}=0.06) \text { and increase in } L V E F \\
(\mathrm{P}<0.01) \\
\text { Suppressed ventricular arrhythmias and } \\
\text { increased } L V E F \text { vs placebo }(\mathrm{P}<0.001)\end{array}$ & $\begin{array}{l}\text { Hammer et al., } 1989 \\
\text { Singh et al., } 1995\end{array}$ \\
\hline Perhexiline & $\begin{array}{l}\text { Reversible CPT1 } \\
\text { inhibitor }\end{array}$ & $\begin{array}{l}\text { Fatty acid oxidation } \\
\text { inhibition }\end{array}$ & $\begin{array}{c}\text { FDA approved } \\
\text { Refractory angina }\end{array}$ & Phase II & $\begin{array}{l}30 \% \text { increase in } P C r / A T P \text { ratio }(P<0.01) \\
\text { Improvement in NYHA functional class vs } \\
\text { placebo }(P=0.036) \\
\text { Improvement in peak exercise oxygen } \\
\text { consumption }(P<0.001) \text {, quality of life } \\
(P=0.04) \text { and } L V E F(P<0.001)\end{array}$ & $\begin{array}{l}\text { Beadle et al., } 2015 \\
\text { Lee et al., } 2005\end{array}$ \\
\hline Trimetazidine & $\begin{array}{l}\text { LC 3-KAT inhibitor } \\
\text { Weak CPT1 inhibitor }\end{array}$ & $\begin{array}{l}\text { Fatty acid oxidation } \\
\text { inhibition }\end{array}$ & $\begin{array}{l}\text { FDA approved } \\
\text { Angina }\end{array}$ & Phase II & $\begin{array}{l}\text { Increase in LVEF ( } P=0.002) \text {, improvement } \\
\text { in NYHA functional class }(P<0.0001)\end{array}$ & Fragasso et al., 2006 \\
\hline Ranolazine & $\begin{array}{l}\text { Partial LC 3-KAT } \\
\text { inhibitor }\end{array}$ & $\begin{array}{l}\text { Fatty acid oxidation } \\
\text { inhibition }\end{array}$ & $\begin{array}{l}\text { FDA approved } \\
\text { Angina }\end{array}$ & Phase II & $\begin{array}{l}\text { Reduced LV end-diastolic pressure and } \\
\text { PCWP vs placebo }(P=0.04) \\
\text { Increase in LVEF in HFrEF patients } \\
(P=0.001) \text { and HFpEF patients }(P=0.003) \\
\text { Vs placebo }\end{array}$ & $\begin{array}{l}\text { Maier et al., } 2013 \\
\text { Murray and Colombo, } \\
2014\end{array}$ \\
\hline $\begin{array}{l}\text { Malonyl-CoA } \\
\text { decarboxylase } \\
\text { gene silencer }\end{array}$ & $\begin{array}{l}\text { Malonyl-CoA } \\
\text { decarboxylase } \\
\text { inhibitor }\end{array}$ & $\begin{array}{l}\text { Fatty acid oxidation } \\
\text { inhibition }\end{array}$ & \multicolumn{2}{|c|}{ Pre-clinical data only } & $\begin{array}{l}\text { Coronary artery ligated mice: } \\
31 \% \text { higher LVEF in MCD knock-out vs } \\
\text { wild-type mice } \\
\text { Increase in ATP production }(\mathrm{P}<0.05)\end{array}$ & Masoud et al., 2014 \\
\hline Fenofibrate & PPAR $\alpha$ agonist & $\begin{array}{l}\text { Fatty acid oxidation } \\
\text { stimulation }\end{array}$ & $\begin{array}{l}\text { FDA approved } \\
\text { hypercholesterolemia }\end{array}$ & Pre-clinical data only & $\begin{array}{l}\text { Cultured HPAECs from HFrEF patients: } \\
\text { Improved endothelial function vs control } \\
(\mathrm{P}<0.05) \\
\text { Isolated PBMCs from HF patients: } \\
\text { Improved endothelial function vs control }\end{array}$ & $\begin{array}{l}\text { Yin, Chen et al., } 2013 \\
\text { Huang et al., } 2009\end{array}$ \\
\hline
\end{tabular}




\begin{tabular}{|c|c|c|c|c|c|c|}
\hline & & & & & $(P=0.0121)$ & \\
\hline Gemfibrozil & PPAR $\alpha$ agonist & $\begin{array}{l}\text { Fatty acid oxidation } \\
\text { stimulation }\end{array}$ & $\begin{array}{c}\text { FDA approved } \\
\text { hypercholesterolemia }\end{array}$ & Pre-clinical data only & $\begin{array}{l}\text { Abdominal aortic constricted rats: } \\
\text { Reduced oxidative stress and } \\
\text { hypertrophy }(\mathrm{P}<0.05)\end{array}$ & Singh et al., 2014a \\
\hline Resveratrol & SIRT1 activator & $\begin{array}{l}\text { Fatty acid oxidation } \\
\text { stimulation; } \\
\text { Mitochondrial ROS } \\
\text { scavenging }\end{array}$ & $\begin{array}{c}\text { FDA approved } \\
\text { As dietary supplement }\end{array}$ & Pre-clinical data only & $\begin{array}{l}\text { Mouse myoblast cell-line: } \\
\text { Increased resistance to oxidative stress } \\
(\mathrm{P}<0.05) \\
\text { Cardiomyocytes from failing hamster } \\
\text { hearts: } \\
\text { Suppressed fibrosis, preserved cardiac } \\
\text { function, and improved survival }(\mathrm{P}<0.05)\end{array}$ & $\begin{array}{l}\text { Tanno et al., } 2010 \\
\text { Gu et al., } 2014\end{array}$ \\
\hline GIK infusion & Glucose and insulin & $\begin{array}{l}\text { Increases glucose } \\
\text { oxidation }\end{array}$ & $\begin{array}{c}\text { FDA approved } \\
\text { Type } 2 \text { diabetes } \\
\text { mellitus } \\
\text { Ischemic heart disease }\end{array}$ & Phase II & $\begin{array}{l}\text { Increase in LVEF } 1 \text { week }(P=0.001) \text { and } 1 \\
\text { month }(P=0.01) \text { post-treatment, reduced } \\
\text { BNP }(P=0.01) \text { vs placebo } \\
\text { Increase in LVEF }(P<0.0001)\end{array}$ & $\begin{array}{l}\text { Kalay et al., } 2008 \\
\text { Nicolas-Robin et al., } 2008\end{array}$ \\
\hline Exenatide & GLP-1 agonist & $\begin{array}{l}\text { Increases insulin } \\
\text { release; } \\
\text { Glucose oxidation } \\
\text { stimulation }\end{array}$ & $\begin{array}{l}\text { FDA approved } \\
\text { Type } 2 \text { diabetes } \\
\text { mellitus }\end{array}$ & Phase II & $\begin{array}{l}\text { Increased cardiac index }(P=0.003) \text { and } \\
\text { improved PCWP }(P=0.001)\end{array}$ & Nathanson et al., 2012 \\
\hline Dichloroacetate & $\begin{array}{l}\text { PDK inhibitor } \\
\text { (pyruvate analogue) }\end{array}$ & $\begin{array}{l}\text { Glucose oxidation } \\
\text { stimulation }\end{array}$ & / & Phase II & $\begin{array}{l}\text { Improved left ventricular mechanical } \\
\text { efficiency }(P=0.03) \text { and reduction in } \\
\text { myocardial oxygen consumption } \\
(P=0.06)\end{array}$ & Bersin et al., 1994 \\
\hline Metformin & $\begin{array}{l}\text { Biguanide oral } \\
\text { hypoglycaemic agent; } \\
\text { Indirect AMPK } \\
\text { activation }\end{array}$ & $\begin{array}{l}\text { Glucose oxidation } \\
\text { stimulation }\end{array}$ & $\begin{array}{l}\text { FDA approved } \\
\text { Type } 2 \text { diabetes } \\
\text { mellitus }\end{array}$ & $\begin{array}{l}\text { Pre-clinical data only } \\
\text { Phase II trial aborted }\end{array}$ & $\begin{array}{l}\text { Canine rapid pacing HF: } \\
\text { Reduced LV end-diastolic pressure and } \\
\text { PCWP, reduced BNP expression }(\mathrm{P}<0.05) \\
\text { Reduced cardiac fibrosis }(\mathrm{P}<0.01) \text { and } \\
\text { improved LV end-diastolic pressure } \\
(\mathrm{P}<0.05) \\
\text { Trial aborted due to patient recruitment } \\
\text { as they were on therapies that were } \\
\text { contraindicated }\end{array}$ & $\begin{array}{l}\text { Sasaki et al., } 2009 \\
\text { Xiao et al., } 2010 \\
\text { Eurich et al., } 2009\end{array}$ \\
\hline Coenzyme Q10 & $\begin{array}{l}\text { Important component } \\
\text { of ETC; Antioxidant }\end{array}$ & $\begin{array}{l}\text { Mitochondrial ROS } \\
\text { scavenging }\end{array}$ & $\begin{array}{c}\text { FDA approved } \\
\text { As dietary supplement }\end{array}$ & Phase II & $\begin{array}{l}\text { Reduced cardiovascular mortality } \\
(P=0.026) \text {, all-cause mortality }(P=0.018) \\
\text { and hospital stay }(P=0.033) \text { vs placebo. }\end{array}$ & Mortensen et al., 2014 \\
\hline
\end{tabular}




\begin{tabular}{|c|c|c|c|c|c|c|}
\hline & & & & & $\begin{array}{l}\text { Improvement in NYHA functional class ( } \\
P=0.028 \text { ) after } 2 \text { years }\end{array}$ & \\
\hline MitoQ & $\begin{array}{l}\text { Selective } \\
\text { mitochondria-targeted } \\
\text { antioxidant }\end{array}$ & $\begin{array}{l}\text { Mitochondrial ROS } \\
\text { scavenging }\end{array}$ & $\begin{array}{c}\text { FDA approved } \\
\text { As dietary supplement }\end{array}$ & Pre-clinical data only & $\begin{array}{l}\text { Spontaneously hypertensive rats: } \\
\text { Reduced hypertrophy }(\mathrm{P}=0.002) \text { and } \\
\text { reduced systolic blood pressure } \\
(\mathrm{P}=0.0001) \text { and improved endothelial } \\
\text { function vs control }\end{array}$ & Graham et al., 2009 \\
\hline SS31 & $\begin{array}{l}\text { Selective } \\
\text { mitochondria-targeted } \\
\text { antioxidant }\end{array}$ & $\begin{array}{l}\text { Cardiolipin } \\
\text { stabilization; } \\
\text { Mitochondrial ROS } \\
\text { scavenging }\end{array}$ & / & Pre-clinical data only & $\begin{array}{l}\text { Transverse aortic constricted mice: } \\
\text { Reduced hypertrophy }(P<0.05) \text {, fibrosis } \\
(P=0.005) \text { and abolished mitochondrial } \\
\text { oxidative damage }(P<0.05) \text { vs control }\end{array}$ & Dai et al., 2013 \\
\hline Elamipretide & $\begin{array}{l}\text { Selective } \\
\text { mitochondria-targeted } \\
\text { antioxidant }\end{array}$ & $\begin{array}{l}\text { Cardiolipin } \\
\text { stabilization; } \\
\text { Cardiolipin peroxidase } \\
\text { inhibition }\end{array}$ & / & $\begin{array}{l}\text { Pre-clinical data only - } \\
\text { Phase II trials commenced }\end{array}$ & $\begin{array}{l}\text { Canine microembolization-induced HF: } \\
\text { Increase in LVEF }(P<0.05) \text {, reduced } \\
\text { plasma BNP }(P<0.001) \text { and increased } \\
\text { ATP/ADP ratio }(P<0.001) \text { vs placebo }\end{array}$ & $\begin{array}{l}\text { Sabbah et al., } 2016 \\
\text { NCT02788747 } \\
\text { NCT02814097 }\end{array}$ \\
\hline Allopurinol & $\begin{array}{l}\text { Xanthine oxidase } \\
\text { inhibitor }\end{array}$ & $\begin{array}{l}\text { Mitochondrial ROS } \\
\text { scavenging }\end{array}$ & $\begin{array}{l}\text { FDA approved } \\
\text { For hyperuricemia }\end{array}$ & Phase II & $\begin{array}{l}\text { Increased cardiac } P C r / A T P \text { ratio }(P<0.02) \\
\text { and mean } C K \text { flux }(P<0.007) \text { vs placebo }\end{array}$ & Hirsch et al., 2012 \\
\hline
\end{tabular}




\section{References}

Abozguia, K., Elliott, P., McKenna, W., Phan, T. T., Nallur-Shivu, G., Ahmed, I., et al. (2010). Metabolic modulator perhexiline corrects energy deficiency and improves exercise capacity in symptomatic hypertrophic cardiomyopathy. Circulation, 122, 1562-1569.

Akkafa, F., Halil Altiparmak, I., Erkus, M. E., Aksoy, N., Kaya, C., Ozer, A., et al. (2015). Reduced SIRT1 expression correlates with enhanced oxidative stress in compensated and decompensated heart failure. Redox Biol, 6, 169-173.

Akki, A., Smith, K., \& Seymour, A. M. (2008). Compensated cardiac hypertrophy is characterised by a decline in palmitate oxidation. Mol Cell Biochem, 311, 215-224.

Arany, Z., Novikov, M., Chin, S., Ma, Y., Rosenzweig, A., \& Spiegelman, B. M. (2006). Transverse aortic constriction leads to accelerated heart failure in mice lacking PPAR-gamma coactivator 1alpha. Proc Natl Acad Sci U S A, 103, 10086-10091.

Armstrong, M. L. (1973). Proceedings: A comparative study of perhexiline, beta-adrenergic blocking agents and placebos in the management of angina pectoris. Postgrad Med J, 49, Suppl 3:108-112.

Ashrafian, H., Frenneaux, M. P., \& Opie, L. H. (2007). Metabolic mechanisms in heart failure. Circulation, 116, 434-448.

Ashrafian, H., Horowitz, J. D., \& Frenneaux, M. P. (2007). Perhexiline. Cardiovasc Drug Rev, 25, 76-97.

Atherton, J. J., Moore, T. D., Lele, S. S., Thomson, H. L., Galbraith, A. J., Belenkie, I., et al. (1997). Diastolic ventricular interaction in chronic heart failure. Lancet, 349, 1720-1724.

Aubert, G., Martin, O. J., Horton, J. L., Lai, L., Vega, R. B., Leone, T. C., et al. (2016). The Failing Heart Relies on Ketone Bodies as a Fuel. Circulation, 133, 698-705.

Azzu, V., \& Brand, M. D. (2010). The on-off switches of the mitochondrial uncoupling proteins. Trends Biochem Sci, 35, 298-307.

Balgi, A. D., Fonseca, B. D., Donohue, E., Tsang, T. C., Lajoie, P., Proud, C. G., et al. (2009). Screen for chemical modulators of autophagy reveals novel therapeutic inhibitors of mTORC1 signaling. PLoS One, 4, e7124.

Barger, P. M., Brandt, J. M., Leone, T. C., Weinheimer, C. J., \& Kelly, D. P. (2000). Deactivation of peroxisome proliferator-activated receptor-alpha during cardiac hypertrophic growth. J Clin Invest, $105,1723-1730$.

Barlaka, E., Gorbe, A., Gaspar, R., Paloczi, J., Ferdinandy, P., \& Lazou, A. (2015). Activation of PPARbeta/delta protects cardiac myocytes from oxidative stress-induced apoptosis by suppressing generation of reactive oxygen/nitrogen species and expression of matrix metalloproteinases. Pharmacol Res, 95-96, 102-110.

Bartha, E., Solti, I., Kereskai, L., Lantos, J., Plozer, E., Magyar, K., et al. (2009). PARP inhibition delays transition of hypertensive cardiopathy to heart failure in spontaneously hypertensive rats. Cardiovasc Res, 83, 501-510.

Bayeva, M., Gheorghiade, M., \& Ardehali, H. (2013). Mitochondria as a therapeutic target in heart failure. J Am Coll Cardiol, 61, 599-610. 
Beadle, R., \& Frenneaux, M. (2010). Magnetic resonance spectroscopy in myocardial disease. Expert Rev Cardiovasc Ther, 8, 269-277.

Beadle, R. M., Williams, L. K., Kuehl, M., Bowater, S., Abozguia, K., Leyva, F., et al. (2015). Improvement in cardiac energetics by perhexiline in heart failure due to dilated cardiomyopathy. JACC Heart Fail, 3, 202-211.

Bedi, K. C., Jr., Snyder, N. W., Brandimarto, J., Aziz, M., Mesaros, C., Worth, A. J., et al. (2016). Evidence for Intramyocardial Disruption of Lipid Metabolism and Increased Myocardial Ketone Utilization in Advanced Human Heart Failure. Circulation, 133, 706-716.

Beer, M., Seyfarth, T., Sandstede, J., Landschutz, W., Lipke, C., Kostler, H., et al. (2002). Absolute concentrations of high-energy phosphate metabolites in normal, hypertrophied, and failing human myocardium measured noninvasively with (31)P-SLOOP magnetic resonance spectroscopy. J Am Coll Cardiol, 40, 1267-1274.

Bersin, R. M., Wolfe, C., Kwasman, M., Lau, D., Klinski, C., Tanaka, K., et al. (1994). Improved hemodynamic function and mechanical efficiency in congestive heart failure with sodium dichloroacetate. J Am Coll Cardiol, 23, 1617-1624.

Bing, R. J., Siegel, A., Ungar, I., \& Gilbert, M. (1954). Metabolism of the human heart. II. Studies on fat, ketone and amino acid metabolism. Am J Med, 16, 504-515.

Bockhardt, H., Drenckhahn, D., \& Lullmann-Rauch, R. (1978). Amiodarone-induced lipidosis-like alterations in ocular tissues of rats. Albrecht Von Graefes Arch Klin Exp Ophthalmol, 207, 91-96.

Borbely, A., Falcao-Pires, I., van Heerebeek, L., Hamdani, N., Edes, I., Gavina, C., et al. (2009). Hypophosphorylation of the Stiff N2B titin isoform raises cardiomyocyte resting tension in failing human myocardium. Circ Res, 104, 780-786.

Borbely, A., van der Velden, J., Papp, Z., Bronzwaer, J. G., Edes, I., Stienen, G. J., et al. (2005). Cardiomyocyte stiffness in diastolic heart failure. Circulation, 111, 774-781.

Borlaug, B. A., \& Kass, D. A. (2011). Ventricular-vascular interaction in heart failure. Cardiol Clin, 29, 447-459.

Borlaug, B. A., Koepp, K. E., \& Melenovsky, V. (2015). Sodium Nitrite Improves Exercise Hemodynamics and Ventricular Performance in Heart Failure With Preserved Ejection Fraction. J Am Coll Cardiol, 66, 1672-1682.

Borlaug, B. A., Lam, C. S., Roger, V. L., Rodeheffer, R. J., \& Redfield, M. M. (2009). Contractility and ventricular systolic stiffening in hypertensive heart disease insights into the pathogenesis of heart failure with preserved ejection fraction. J Am Coll Cardiol, 54, 410-418.

Borlaug, B. A., Melenovsky, V., \& Koepp, K. E. (2016). Inhaled Sodium Nitrite Improves Rest and Exercise Hemodynamics in Heart Failure With Preserved Ejection Fraction. Circ Res, 119, 880-886.

Borlaug, B. A., Melenovsky, V., Redfield, M. M., Kessler, K., Chang, H. J., Abraham, T. P., et al. (2007). Impact of arterial load and loading sequence on left ventricular tissue velocities in humans. J Am Coll Cardiol, 50, 1570-1577. 
Borlaug, B. A., Nishimura, R. A., Sorajja, P., Lam, C. S., \& Redfield, M. M. (2010). Exercise hemodynamics enhance diagnosis of early heart failure with preserved ejection fraction. Circ Heart Fail, 3, 588-595.

Borlaug, B. A., \& Paulus, W. J. (2011). Heart failure with preserved ejection fraction: pathophysiology, diagnosis, and treatment. Eur Heart J, 32, 670-679.

Bristow, M. R., Ginsburg, R., Minobe, W., Cubicciotti, R. S., Sageman, W. S., Lurie, K., et al. (1982). Decreased catecholamine sensitivity and beta-adrenergic-receptor density in failing human hearts. $N$ Engl J Med, 307, 205-211.

Bugger, H., Schwarzer, M., Chen, D., Schrepper, A., Amorim, P. A., Schoepe, M., et al. (2010). Proteomic remodelling of mitochondrial oxidative pathways in pressure overload-induced heart failure. Cardiovasc Res, 85, 376-384.

Bui, A. L., Horwich, T. B., \& Fonarow, G. C. (2011). Epidemiology and risk profile of heart failure. Nat Rev Cardiol, 8, 30-41.

Bursi, F., Weston, S. A., Redfield, M. M., Jacobsen, S. J., Pakhomov, S., Nkomo, V. T., et al. (2006). Systolic and diastolic heart failure in the community. Jama, 296, 2209-2216.

Calcutt, N. A., Lopez, V. L., Bautista, A. D., Mizisin, L. M., Torres, B. R., Shroads, A. L., et al. (2009). Peripheral neuropathy in rats exposed to dichloroacetate. J Neuropathol Exp Neurol, 68, 985-993.

Carley, A. N., \& Lewandowski, E. D. (2016). Triacylglycerol turnover in the failing heart. Biochim Biophys Acta, 1860, 1492-1499.

Cave, A. C., Ingwall, J. S., Friedrich, J., Liao, R., Saupe, K. W., Apstein, C. S., et al. (2000). ATP synthesis during low-flow ischemia: influence of increased glycolytic substrate. Circulation, 101, 2090-2096.

Chaitman, B. R., Pepine, C. J., Parker, J. O., Skopal, J., Chumakova, G., Kuch, J., et al. (2004). Effects of ranolazine with atenolol, amlodipine, or diltiazem on exercise tolerance and angina frequency in patients with severe chronic angina: a randomized controlled trial. Jama, 291, 309-316.

Chan, A. Y., Soltys, C. L., Young, M. E., Proud, C. G., \& Dyck, J. R. (2004). Activation of AMP-activated protein kinase inhibits protein synthesis associated with hypertrophy in the cardiac myocyte. $J$ Biol Chem, 279, 32771-32779.

Chance, B., Im, J., Nioka, S., \& Kushmerick, M. (2006). Skeletal muscle energetics with PNMR: personal views and historic perspectives. NMR Biomed, 19, 904-926.

Chandel, N. S., McClintock, D. S., Feliciano, C. E., Wood, T. M., Melendez, J. A., Rodriguez, A. M., et al. (2000). Reactive oxygen species generated at mitochondrial complex III stabilize hypoxia-inducible factor-1alpha during hypoxia: a mechanism of O2 sensing. J Biol Chem, 275, 25130-25138.

Chandran, K., Aggarwal, D., Migrino, R. Q., Joseph, J., McAllister, D., Konorev, E. A., et al. (2009). Doxorubicin inactivates myocardial cytochrome $\mathrm{c}$ oxidase in rats: cardioprotection by Mito-Q. Biophys J, 96, 1388-1398.

Chen, A. D., Zhang, S. J., Yuan, N., Xu, Y., De, W., Gao, X. Y., et al. (2011). Angiotensin AT1 receptors in paraventricular nucleus contribute to sympathetic activation and enhanced cardiac sympathetic afferent reflex in renovascular hypertensive rats. Exp Physiol, 96, 94-103. 
Chen, C. H., Fetics, B., Nevo, E., Rochitte, C. E., Chiou, K. R., Ding, P. A., et al. (2001). Noninvasive single-beat determination of left ventricular end-systolic elastance in humans. J Am Coll Cardiol, 38, 2028-2034.

Chen, T., Liu, J., Li, N., Wang, S., Liu, H., Li, J., et al. (2015). Mouse SIRT3 attenuates hypertrophyrelated lipid accumulation in the heart through the deacetylation of LCAD. PLoS One, 10, e0118909.

Cheng, J. F., Chen, M., Wallace, D., Tith, S., Haramura, M., Liu, B., et al. (2006). Synthesis and structure-activity relationship of small-molecule malonyl coenzyme A decarboxylase inhibitors. J Med Chem, 49, 1517-1525.

Chess, D. J., Khairallah, R. J., O'Shea, K. M., Xu, W., \& Stanley, W. C. (2009). A high-fat diet increases adiposity but maintains mitochondrial oxidative enzymes without affecting development of heart failure with pressure overload. Am J Physiol Heart Circ Physiol, 297, H1585-1593.

Chokshi, A., Drosatos, K., Cheema, F. H., Ji, R., Khawaja, T., Yu, S., et al. (2012). Ventricular assist device implantation corrects myocardial lipotoxicity, reverses insulin resistance, and normalizes cardiac metabolism in patients with advanced heart failure. Circulation, 125, 2844-2853.

Chong, C. R., Chan, W. P., Nguyen, T. H., Liu, S., Procter, N. E., Ngo, D. T., et al. (2014). Thioredoxininteracting protein: pathophysiology and emerging pharmacotherapeutics in cardiovascular disease and diabetes. Cardiovasc Drugs Ther, 28, 347-360.

Chong, C. R., Sallustio, B., \& Horowitz, J. D. (2016). Drugs that Affect Cardiac Metabolism: Focus on Perhexiline. Cardiovasc Drugs Ther, 30, 399-405.

Circu, M. L., \& Aw, T. Y. (2010). Reactive oxygen species, cellular redox systems, and apoptosis. Free Radic Biol Med, 48, 749-762.

Cole, P. L., Beamer, A. D., McGowan, N., Cantillon, C. O., Benfell, K., Kelly, R. A., et al. (1990). Efficacy and safety of perhexiline maleate in refractory angina. A double-blind placebo-controlled clinical trial of a novel antianginal agent. Circulation, 81, 1260-1270.

Cotter, D. G., Schugar, R. C., \& Crawford, P. A. (2013). Ketone body metabolism and cardiovascular disease. Am J Physiol Heart Circ Physiol, 304, H1060-1076.

Cowley, A. W., Jr., Abe, M., Mori, T., O'Connor, P. M., Ohsaki, Y., \& Zheleznova, N. N. (2015). Reactive oxygen species as important determinants of medullary flow, sodium excretion, and hypertension. Am J Physiol Renal Physiol, 308, F179-197.

Cunningham, C. H., Lau, J. Y., Chen, A. P., Geraghty, B. J., Perks, W. J., Roifman, I., et al. (2016). Hyperpolarized 13C Metabolic MRI of the Human Heart: Initial Experience. Circ Res, 119, 1177-1182.

Dai, D. F., Chen, T., Szeto, H., Nieves-Cintron, M., Kutyavin, V., Santana, L. F., et al. (2011). Mitochondrial targeted antioxidant Peptide ameliorates hypertensive cardiomyopathy. J Am Coll Cardiol, 58, 73-82.

Dai, D. F., Hsieh, E. J., Chen, T., Menendez, L. G., Basisty, N. B., Tsai, L., et al. (2013). Global proteomics and pathway analysis of pressure-overload-induced heart failure and its attenuation by mitochondrial-targeted peptides. Circ Heart Fail, 6, 1067-1076. 
Dai, D. F., Hsieh, E. J., Liu, Y., Chen, T., Beyer, R. P., Chin, M. T., et al. (2012). Mitochondrial proteome remodelling in pressure overload-induced heart failure: the role of mitochondrial oxidative stress. Cardiovasc Res, 93, 79-88.

Davies, B. J., Coller, J. K., James, H. M., Gillis, D., Somogyi, A. A., Horowitz, J. D., et al. (2004). Clinical inhibition of CYP2D6-catalysed metabolism by the antianginal agent perhexiline. Br J Clin Pharmacol, $57,456-463$.

De Angelis, A., Cappetta, D., Piegari, E., Rinaldi, B., Ciuffreda, L. P., Esposito, G., et al. (2016). Longterm administration of ranolazine attenuates diastolic dysfunction and adverse myocardial remodeling in a model of heart failure with preserved ejection fraction. Int J Cardiol, 217, 69-79.

de Brouwer, K. F., Degens, H., Aartsen, W. M., Lindhout, M., Bitsch, N. J., Gilde, A. J., et al. (2006). Specific and sustained down-regulation of genes involved in fatty acid metabolism is not a hallmark of progression to cardiac failure in mice. J Mol Cell Cardiol, 40, 838-845.

De Meyer, G. R., De Keulenaer, G. W., \& Martinet, W. (2010). Role of autophagy in heart failure associated with aging. Heart Fail Rev, 15, 423-430.

de Roos, A., Doornbos, J., Luyten, P. R., Oosterwaal, L. J., van der Wall, E. E., \& den Hollander, J. A. (1992). Cardiac metabolism in patients with dilated and hypertrophic cardiomyopathy: assessment with proton-decoupled P-31 MR spectroscopy. J Magn Reson Imaging, 2, 711-719.

De Tombe, P. P., Jones, S., Burkhoff, D., Hunter, W. C., \& Kass, D. A. (1993). Ventricular stroke work and efficiency both remain nearly optimal despite altered vascular loading. Am J Physiol, 264, H18171824.

Dhakal, B. P., Malhotra, R., Murphy, R. M., Pappagianopoulos, P. P., Baggish, A. L., Weiner, R. B., et al. (2015). Mechanisms of exercise intolerance in heart failure with preserved ejection fraction: the role of abnormal peripheral oxygen extraction. Circ Heart Fail, 8, 286-294.

Doehner, W., Frenneaux, M., \& Anker, S. D. (2014). Metabolic impairment in heart failure: the myocardial and systemic perspective. J Am Coll Cardiol, 64, 1388-1400.

Doenst, T., Nguyen, T. D., \& Abel, E. D. (2013). Cardiac metabolism in heart failure: implications beyond ATP production. Circ Res, 113, 709-724.

Doenst, T., Pytel, G., Schrepper, A., Amorim, P., Farber, G., Shingu, Y., et al. (2010). Decreased rates of substrate oxidation ex vivo predict the onset of heart failure and contractile dysfunction in rats with pressure overload. Cardiovasc Res, 86, 461-470.

Dyck, J. R., Cheng, J. F., Stanley, W. C., Barr, R., Chandler, M. P., Brown, S., et al. (2004). Malonyl coenzyme a decarboxylase inhibition protects the ischemic heart by inhibiting fatty acid oxidation and stimulating glucose oxidation. Circ Res, 94, e78-84.

Eurich, D. T., Majumdar, S. R., McAlister, F. A., Tsuyuki, R. T., \& Johnson, J. A. (2005). Improved clinical outcomes associated with metformin in patients with diabetes and heart failure. Diabetes Care, 28, 2345-2351.

Eurich, D. T., Tsuyuki, R. T., Majumdar, S. R., McAlister, F. A., Lewanczuk, R., Shibata, M. C., et al. (2009). Metformin treatment in diabetes and heart failure: when academic equipoise meets clinical reality. Trials, 10, 12. 
Fath-Ordoubadi, F., \& Beatt, K. J. (1997). Glucose-insulin-potassium therapy for treatment of acute myocardial infarction: an overview of randomized placebo-controlled trials. Circulation, 96, 11521156.

Feng, G., Yang, Y., Chen, J., Wu, Z., Zheng, Y., Li, W., et al. (2016). Ranolazine attenuated heightened plasma norepinephrine and B-Type natriuretic peptide- 45 in improving cardiac function in rats with chronic ischemic heart failure. Am J Transl Res, 8, 1295-1301.

Fillmore, N., \& Lopaschuk, G. D. (2013). Targeting mitochondrial oxidative metabolism as an approach to treat heart failure. Biochim Biophys Acta, 1833, 857-865.

Fotino, A. D., Thompson-Paul, A. M., \& Bazzano, L. A. (2013). Effect of coenzyme Q(1)(0) supplementation on heart failure: a meta-analysis. Am J Clin Nutr, 97, 268-275.

Fragasso, G., Palloshi, A., Puccetti, P., Silipigni, C., Rossodivita, A., Pala, M., et al. (2006). A randomized clinical trial of trimetazidine, a partial free fatty acid oxidation inhibitor, in patients with heart failure. J Am Coll Cardiol, 48, 992-998.

Fukushima, A., \& Lopaschuk, G. D. (2016). Acetylation control of cardiac fatty acid beta-oxidation and energy metabolism in obesity, diabetes, and heart failure. Biochim Biophys Acta, 1862, 22112220.

Gandhi, S. K., Powers, J. C., Nomeir, A. M., Fowle, K., Kitzman, D. W., Rankin, K. M., et al. (2001). The pathogenesis of acute pulmonary edema associated with hypertension. N Engl J Med, 344, 17-22.

Gatto, G. J., Jr., Ao, Z., Kearse, M. G., Zhou, M., Morales, C. R., Daniels, E., et al. (2013). NADPH oxidase-dependent and -independent mechanisms of reported inhibitors of reactive oxygen generation. J Enzyme Inhib Med Chem, 28, 95-104.

Gavin, A. D., \& Struthers, A. D. (2005). Allopurinol reduces B-type natriuretic peptide concentrations and haemoglobin but does not alter exercise capacity in chronic heart failure. Heart, 91, 749-753.

Gehmlich, K., Dodd, M. S., Allwood, J. W., Kelly, M., Bellahcene, M., Lad, H. V., et al. (2015). Changes in the cardiac metabolome caused by perhexiline treatment in a mouse model of hypertrophic cardiomyopathy. Mol Biosyst, 11, 564-573.

Giblett, J. P., Axell, R. G., White, P. A., Clarke, S. J., McCormick, L., Read, P. A., et al. (2016). Glucagonlike peptide-1 derived cardioprotection does not utilize a KATP-channel dependent pathway: mechanistic insights from human supply and demand ischemia studies. Cardiovasc Diabetol, 15, 99.

Gibson, C. M., Giugliano, R. P., Kloner, R. A., Bode, C., Tendera, M., Janosi, A., et al. (2016). EMBRACE STEMI study: a Phase 2a trial to evaluate the safety, tolerability, and efficacy of intravenous MTP-131 on reperfusion injury in patients undergoing primary percutaneous coronary intervention. Eur Heart J, 37, 1296-1303.

Gilde, A. J., van der Lee, K. A., Willemsen, P. H., Chinetti, G., van der Leij, F. R., van der Vusse, G. J., et al. (2003). Peroxisome proliferator-activated receptor (PPAR) alpha and PPARbeta/delta, but not PPARgamma, modulate the expression of genes involved in cardiac lipid metabolism. Circ Res, 92, 518-524.

Gillebert, T. C., Leite-Moreira, A. F., \& De Hert, S. G. (1997). Relaxation-systolic pressure relation. A load-independent assessment of left ventricular contractility. Circulation, 95, 745-752. 
Graham, D., Huynh, N. N., Hamilton, C. A., Beattie, E., Smith, R. A., Cocheme, H. M., et al. (2009). Mitochondria-targeted antioxidant MitoQ10 improves endothelial function and attenuates cardiac hypertrophy. Hypertension, 54, 322-328.

Gu, X. S., Wang, Z. B., Ye, Z., Lei, J. P., Li, L., Su, D. F., et al. (2014). Resveratrol, an activator of SIRT1, upregulates AMPK and improves cardiac function in heart failure. Genet Mol Res, 13, 323-335.

Guazzi, M., \& Borlaug, B. A. (2012). Pulmonary hypertension due to left heart disease. Circulation, $126,975-990$.

Gundewar, S., Calvert, J. W., Jha, S., Toedt-Pingel, I., Ji, S. Y., Nunez, D., et al. (2009). Activation of AMP-activated protein kinase by metformin improves left ventricular function and survival in heart failure. Circ Res, 104, 403-411.

Guo, Y., Fan, Y., Zhang, J., Lomberk, G. A., Zhou, Z., Sun, L., et al. (2015). Perhexiline activates KLF14 and reduces atherosclerosis by modulating ApoA-I production. J Clin Invest, 125, 3819-3830.

Gwathmey, J. K., Copelas, L., MacKinnon, R., Schoen, F. J., Feldman, M. D., Grossman, W., et al. (1987). Abnormal intracellular calcium handling in myocardium from patients with end-stage heart failure. Circ Res, 61, 70-76.

Hamer, A. W., Arkles, L. B., \& Johns, J. A. (1989). Beneficial effects of low dose amiodarone in patients with congestive cardiac failure: a placebo-controlled trial. J Am Coll Cardiol, 14, 1768-1774.

Handschin, C., \& Spiegelman, B. M. (2008). The role of exercise and PGC1alpha in inflammation and chronic disease. Nature, 454, 463-469.

Hart, C. Y., Meyer, D. M., Tazelaar, H. D., Grande, J. P., Burnett, J. C., Jr., Housmans, P. R., et al. (2001). Load versus humoral activation in the genesis of early hypertensive heart disease. Circulation, 104, 215-220.

Hirasaka, K., Lago, C. U., Kenaston, M. A., Fathe, K., Nowinski, S. M., Nikawa, T., et al. (2011). Identification of a redox-modulatory interaction between uncoupling protein 3 and thioredoxin 2 in the mitochondrial intermembrane space. Antioxid Redox Signal, 15, 2645-2661.

Hirsch, G. A., Bottomley, P. A., Gerstenblith, G., \& Weiss, R. G. (2012). Allopurinol acutely increases adenosine triphospate energy delivery in failing human hearts. J Am Coll Cardiol, 59, 802-808.

Holmstrom, K. M., \& Finkel, T. (2014). Cellular mechanisms and physiological consequences of redoxdependent signalling. Nat Rev Mol Cell Biol, 15, 411-421.

Holscher, M., Schafer, K., Krull, S., Farhat, K., Hesse, A., Silter, M., et al. (2012). Unfavourable consequences of chronic cardiac HIF-1alpha stabilization. Cardiovasc Res, 94, 77-86.

Holubarsch, C. J., Rohrbach, M., Karrasch, M., Boehm, E., Polonski, L., Ponikowski, P., et al. (2007). A double-blind randomized multicentre clinical trial to evaluate the efficacy and safety of two doses of etomoxir in comparison with placebo in patients with moderate congestive heart failure: the ERGO (etomoxir for the recovery of glucose oxidation) study. Clin Sci (Lond), 113, 205-212.

Horowitz, J. D., Chirkov, Y. Y., Kennedy, J. A., \& Sverdlov, A. L. (2010). Modulation of myocardial metabolism: an emerging therapeutic principle. Curr Opin Cardiol, 25, 329-334. 
Horowitz, J. D., Sia, S. T., Macdonald, P. S., Goble, A. J., \& Louis, W. J. (1986). Perhexiline maleate treatment for severe angina pectoris--correlations with pharmacokinetics. Int J Cardiol, 13, 219-229.

Howell, N. J., Ashrafian, H., Drury, N. E., Ranasinghe, A. M., Contractor, H., Isackson, H., et al. (2011). Glucose-insulin-potassium reduces the incidence of low cardiac output episodes after aortic valve replacement for aortic stenosis in patients with left ventricular hypertrophy: results from the Hypertrophy, Insulin, Glucose, and Electrolytes (HINGE) trial. Circulation, 123, 170-177.

Huang, Q., Zhou, H. J., Zhang, H., Huang, Y., Hinojosa-Kirschenbaum, F., Fan, P., et al. (2015). Thioredoxin-2 inhibits mitochondrial reactive oxygen species generation and apoptosis stress kinase1 activity to maintain cardiac function. Circulation, 131, 1082-1097.

Huang, W. P., Yin, W. H., Chen, J. W., Jen, H. L., Young, M. S., \& Lin, S. J. (2009). Fenofibrate attenuates endothelial monocyte adhesion in chronic heart failure: an in vitro study. Eur J Clin Invest, $39,775-783$.

Hue, L., \& Taegtmeyer, H. (2009). The Randle cycle revisited: a new head for an old hat. Am J Physiol Endocrinol Metab, 297, E578-591.

Hunter, W. G., Kelly, J. P., McGarrah, R. W., 3rd, Kraus, W. E., \& Shah, S. H. (2016). Metabolic Dysfunction in Heart Failure: Diagnostic, Prognostic, and Pathophysiologic Insights From Metabolomic Profiling. Curr Heart Fail Rep, 13, 119-131.

Hurd, T. R., Prime, T. A., Harbour, M. E., Lilley, K. S., \& Murphy, M. P. (2007). Detection of reactive oxygen species-sensitive thiol proteins by redox difference gel electrophoresis: implications for mitochondrial redox signaling. J Biol Chem, 282, 22040-22051.

Ide, T., Tsutsui, H., Kinugawa, S., Utsumi, H., Kang, D., Hattori, N., et al. (1999). Mitochondrial electron transport complex I is a potential source of oxygen free radicals in the failing myocardium. Circ Res, 85, 357-363.

Ingwall, J. S. (1984). The hypertrophied myocardium accumulates the MB-creatine kinase isozyme. Eur Heart J, 5 Suppl F, 129-139.

Iwanaga, Y., Nishi, I., Furuichi, S., Noguchi, T., Sase, K., Kihara, Y., et al. (2006). B-type natriuretic peptide strongly reflects diastolic wall stress in patients with chronic heart failure: comparison between systolic and diastolic heart failure. J Am Coll Cardiol, 47, 742-748.

Jackson, G., Gibbs, C. R., Davies, M. K., \& Lip, G. Y. (2000). ABC of heart failure. Pathophysiology. Bmj, $320,167-170$.

Jameel, M. N., Xiong, Q., Mansoor, A., Bache, R. J., \& Zhang, J. (2016). ATP sensitive $K(+)$ channels are critical for maintaining myocardial perfusion and high energy phosphates in the failing heart. $J \mathrm{Mol}$ Cell Cardiol, 92, 116-121.

Jaswal, J. S., Keung, W., Wang, W., Ussher, J. R., \& Lopaschuk, G. D. (2011). Targeting fatty acid and carbohydrate oxidation--a novel therapeutic intervention in the ischemic and failing heart. Biochim Biophys Acta, 1813, 1333-1350.

Kalay, N., Ozdogru, I., Gul, A., Yucel, Y., Cetinkaya, Y., Inanc, M. T., et al. (2008). Effects of intermittent and long-term glucose-insulin-potassium infusion in patients with systolic heart failure. Exp Clin Cardiol, 13, 85-88. 
Kantor, P. F., Lucien, A., Kozak, R., \& Lopaschuk, G. D. (2000). The antianginal drug trimetazidine shifts cardiac energy metabolism from fatty acid oxidation to glucose oxidation by inhibiting mitochondrial long-chain 3-ketoacyl coenzyme A thiolase. Circ Res, 86, 580-588.

Karbowska, J., Kochan, Z., \& Smolenski, R. T. (2003). Peroxisome proliferator-activated receptor alpha is downregulated in the failing human heart. Cell Mol Biol Lett, 8, 49-53.

Kass, D. A., Maughan, W. L., Guo, Z. M., Kono, A., Sunagawa, K., \& Sagawa, K. (1987). Comparative influence of load versus inotropic states on indexes of ventricular contractility: experimental and theoretical analysis based on pressure-volume relationships. Circulation, 76, 1422-1436.

Kato, T., Niizuma, S., Inuzuka, Y., Kawashima, T., Okuda, J., Tamaki, Y., et al. (2010). Analysis of metabolic remodeling in compensated left ventricular hypertrophy and heart failure. Circ Heart Fail, 3, 420-430.

Kawashima, T., Inuzuka, Y., Okuda, J., Kato, T., Niizuma, S., Tamaki, Y., et al. (2011). Constitutive SIRT1 overexpression impairs mitochondria and reduces cardiac function in mice. J Mol Cell Cardiol, 51, 1026-1036.

Kelly, R., Hayward, C., Avolio, A., \& O'Rourke, M. (1989). Noninvasive determination of age-related changes in the human arterial pulse. Circulation, 80, 1652-1659.

Kelly, R. P., Ting, C. T., Yang, T. M., Liu, C. P., Maughan, W. L., Chang, M. S., et al. (1992). Effective arterial elastance as index of arterial vascular load in humans. Circulation, 86, 513-521.

Kennedy, J. A., Beck-Oldach, K., McFadden-Lewis, K., Murphy, G. A., Wong, Y. W., Zhang, Y., et al. (2006). Effect of the anti-anginal agent, perhexiline, on neutrophil, valvular and vascular superoxide formation. Eur J Pharmacol, 531, 13-19.

Kennedy, J. A., Kiosoglous, A. J., Murphy, G. A., Pelle, M. A., \& Horowitz, J. D. (2000). Effect of perhexiline and oxfenicine on myocardial function and metabolism during low-flow ischemia/reperfusion in the isolated rat heart. J Cardiovasc Pharmacol, 36, 794-801.

Kennedy, J. A., Unger, S. A., \& Horowitz, J. D. (1996). Inhibition of carnitine palmitoyltransferase-1 in rat heart and liver by perhexiline and amiodarone. Biochem Pharmacol, 52, 273-280.

Kim, M., Platt, M. J., Shibasaki, T., Quaggin, S. E., Backx, P. H., Seino, S., et al. (2013). GLP-1 receptor activation and Epac2 link atrial natriuretic peptide secretion to control of blood pressure. Nat Med, 19, 567-575.

Kim, T. T., \& Dyck, J. R. (2015). Is AMPK the savior of the failing heart? Trends Endocrinol Metab, 26, 40-48.

Kitzman, D. W., Hundley, W. G., Brubaker, P. H., Morgan, T. M., Moore, J. B., Stewart, K. P., et al. (2010). A randomized double-blind trial of enalapril in older patients with heart failure and preserved ejection fraction: effects on exercise tolerance and arterial distensibility. Circ Heart Fail, 3, 477-485.

Kitzman, D. W., Little, W. C., Brubaker, P. H., Anderson, R. T., Hundley, W. G., Marburger, C. T., et al. (2002). Pathophysiological characterization of isolated diastolic heart failure in comparison to systolic heart failure. Jama, 288, 2144-2150. 
Kober, L., Torp-Pedersen, C., McMurray, J. J., Gotzsche, O., Levy, S., Crijns, H., et al. (2008). Increased mortality after dronedarone therapy for severe heart failure. N Engl J Med, 358, 2678-2687.

Kolobova, E., Tuganova, A., Boulatnikov, I., \& Popov, K. M. (2001). Regulation of pyruvate dehydrogenase activity through phosphorylation at multiple sites. Biochem J, 358, 69-77.

Kolwicz, S. C., Jr., Airhart, S., \& Tian, R. (2016). Ketones Step to the Plate: A Game Changer for Metabolic Remodeling in Heart Failure? Circulation, 133, 689-691.

Kolwicz, S. C., Jr., Olson, D. P., Marney, L. C., Garcia-Menendez, L., Synovec, R. E., \& Tian, R. (2012). Cardiac-specific deletion of acetyl CoA carboxylase 2 prevents metabolic remodeling during pressure-overload hypertrophy. Circ Res, 111, 728-738.

Krishnan, J., Suter, M., Windak, R., Krebs, T., Felley, A., Montessuit, C., et al. (2009). Activation of a HIF1alpha-PPARgamma axis underlies the integration of glycolytic and lipid anabolic pathways in pathologic cardiac hypertrophy. Cell Metab, 9, 512-524.

Ky, B., French, B., May Khan, A., Plappert, T., Wang, A., Chirinos, J. A., et al. (2013). Ventriculararterial coupling, remodeling, and prognosis in chronic heart failure. J Am Coll Cardiol, 62, 11651172.

Labinskyy, V., Bellomo, M., Chandler, M. P., Young, M. E., Lionetti, V., Qanud, K., et al. (2007). Chronic activation of peroxisome proliferator-activated receptor-alpha with fenofibrate prevents alterations in cardiac metabolic phenotype without changing the onset of decompensation in pacing-induced heart failure. J Pharmacol Exp Ther, 321, 165-171.

Lahey, R., Wang, X., Carley, A. N., \& Lewandowski, E. D. (2014). Dietary fat supply to failing hearts determines dynamic lipid signaling for nuclear receptor activation and oxidation of stored triglyceride. Circulation, 130, 1790-1799.

Lam, V. H., Zhang, L., Huqi, A., Fukushima, A., Tanner, B. A., Onay-Besikci, A., et al. (2015). Activating PPARalpha prevents post-ischemic contractile dysfunction in hypertrophied neonatal hearts. Circ Res, 117, 41-51.

Langsjoen, P. H., Vadhanavikit, S., \& Folkers, K. (1985). Response of patients in classes III and IV of cardiomyopathy to therapy in a blind and crossover trial with coenzyme Q10. Proc Natl Acad Sci U S A, 82, 4240-4244.

Le Gall, J. Y., Guillouzo, A., Glaise, D., Deugnier, Y., Messner, M., \& Bourel, M. (1980). Perhexiline maleate toxicity on human liver cell lines. Gut, 21, 977-984.

Lee, C. F., \& Tian, R. (2015). Mitochondrion as a Target for Heart Failure Therapy- Role of Protein Lysine Acetylation. Circ J, 79, 1863-1870.

Lee, L., Campbell, R., Scheuermann-Freestone, M., Taylor, R., Gunaruwan, P., Williams, L., et al. (2005). Metabolic modulation with perhexiline in chronic heart failure: a randomized, controlled trial of short-term use of a novel treatment. Circulation, 112, 3280-3288.

Lee, L., Horowitz, J., \& Frenneaux, M. (2004). Metabolic manipulation in ischaemic heart disease, a novel approach to treatment. Eur Heart J, 25, 634-641. 
Lei, B., Lionetti, V., Young, M. E., Chandler, M. P., d'Agostino, C., Kang, E., et al. (2004). Paradoxical downregulation of the glucose oxidation pathway despite enhanced flux in severe heart failure. $J$ Mol Cell Cardiol, 36, 567-576.

Lei, L., Mason, S., Liu, D., Huang, Y., Marks, C., Hickey, R., et al. (2008). Hypoxia-inducible factordependent degeneration, failure, and malignant transformation of the heart in the absence of the von Hippel-Lindau protein. Mol Cell Biol, 28, 3790-3803.

Lele, S. S., Macfarlane, D., Morrison, S., Thomson, H., Khafagi, F., \& Frenneaux, M. (1996). Determinants of exercise capacity in patients with coronary artery disease and mild to moderate systolic dysfunction. Role of heart rate and diastolic filling abnormalities. Eur Heart J, 17, 204-212.

Lewis, J. F., DaCosta, M., Wargowich, T., \& Stacpoole, P. (1998). Effects of dichloroacetate in patients with congestive heart failure. Clin Cardiol, 21, 888-892.

Li, P., Luo, S., Pan, C., \& Cheng, X. (2015). Modulation of fatty acid metabolism is involved in the alleviation of isoproterenol-induced rat heart failure by fenofibrate. Mol Med Rep, 12, 7899-7906.

Li, Y., Chen, C., Yao, F., Su, Q., Liu, D., Xue, R., et al. (2014). AMPK inhibits cardiac hypertrophy by promoting autophagy via mTORC1. Arch Biochem Biophys, 558, 79-86.

Li, Y. J., Wang, P. H., Chen, C., Zou, M. H., \& Wang, D. W. (2010). Improvement of mechanical heart function by trimetazidine in db/db mice. Acta Pharmacol Sin, 31, 560-569.

Liberts, E. A., Willoughby, S. R., Kennedy, J. A., \& Horowitz, J. D. (2007). Effects of perhexiline and nitroglycerin on vascular, neutrophil and platelet function in patients with stable angina pectoris. Eur J Pharmacol, 560, 49-55.

Lindman, B. R., Davila-Roman, V. G., Mann, D. L., McNulty, S., Semigran, M. J., Lewis, G. D., et al. (2014). Cardiovascular phenotype in HFpEF patients with or without diabetes: a RELAX trial ancillary study. J Am Coll Cardiol, 64, 541-549.

Lionetti, V., Linke, A., Chandler, M. P., Young, M. E., Penn, M. S., Gupte, S., et al. (2005). Carnitine palmitoyl transferase-I inhibition prevents ventricular remodeling and delays decompensation in pacing-induced heart failure. Cardiovasc Res, 66, 454-461.

Lohse, M. J. (1995). G-protein-coupled receptor kinases and the heart. Trends Cardiovasc Med, 5, 6368.

Lopaschuk, G. D., Belke, D. D., Gamble, J., Itoi, T., \& Schonekess, B. O. (1994). Regulation of fatty acid oxidation in the mammalian heart in health and disease. Biochim Biophys Acta, 1213, 263-276.

Lopaschuk, G. D., Ussher, J. R., Folmes, C. D., Jaswal, J. S., \& Stanley, W. C. (2010). Myocardial fatty acid metabolism in health and disease. Physiol Rev, 90, 207-258.

Lother, A., \& Hein, L. (2016). Pharmacology of heart failure: From basic science to novel therapies. Pharmacol Ther, 166, 136-149.

Loudon, B. L., Noordali, H., Gollop, N. D., Frenneaux, M. P., \& Madhani, M. (2016). Present and future pharmacotherapeutic agents in heart failure: an evolving paradigm. Br J Pharmacol, 173, 1911-1924. 
Lu, T. M., Tsai, J. Y., Chen, Y. C., Huang, C. Y., Hsu, H. L., Weng, C. F., et al. (2014). Downregulation of Sirt1 as aging change in advanced heart failure. J Biomed Sci, 21, 57.

Lu, Z., Xu, X., Hu, X., Fassett, J., Zhu, G., Tao, Y., et al. (2010). PGC-1 alpha regulates expression of myocardial mitochondrial antioxidants and myocardial oxidative stress after chronic systolic overload. Antioxid Redox Signal, 13, 1011-1022.

Madsbad, S., Schmitz, O., Ranstam, J., Jakobsen, G., \& Matthews, D. R. (2004). Improved glycemic control with no weight increase in patients with type 2 diabetes after once-daily treatment with the long-acting glucagon-like peptide 1 analog liraglutide (NN2211): a 12-week, double-blind, randomized, controlled trial. Diabetes Care, 27, 1335-1342.

Maier, L. S., Layug, B., Karwatowska-Prokopczuk, E., Belardinelli, L., Lee, S., Sander, J., et al. (2013). RAnoLazIne for the treatment of diastolic heart failure in patients with preserved ejection fraction: the RALI-DHF proof-of-concept study. JACC Heart Fail, 1, 115-122.

Maldonado, E. N., \& Lemasters, J. J. (2014). ATP/ADP ratio, the missed connection between mitochondria and the Warburg effect. Mitochondrion, 19 Pt A, 78-84.

Mamas, M. A., Neyses, L., \& Fath-Ordoubadi, F. (2010). A meta-analysis of glucose-insulin-potassium therapy for treatment of acute myocardial infarction. Exp Clin Cardiol, 15, e20-24.

Mann, D. L., Kent, R. L., Parsons, B., \& Cooper, G. t. (1992). Adrenergic effects on the biology of the adult mammalian cardiocyte. Circulation, 85, 790-804.

Marti Masso, J. F., Marti, I., Carrera, N., Poza, J. J., \& Lopez de Munain, A. (2005). Trimetazidine induces parkinsonism, gait disorders and tremor. Therapie, 60, 419-422.

Masoud, W. G., Ussher, J. R., Wang, W., Jaswal, J. S., Wagg, C. S., Dyck, J. R., et al. (2014). Failing mouse hearts utilize energy inefficiently and benefit from improved coupling of glycolysis and glucose oxidation. Cardiovasc Res, 101, 30-38.

Massie, B. M., Carson, P. E., McMurray, J. J., Komajda, M., McKelvie, R., Zile, M. R., et al. (2008). Irbesartan in patients with heart failure and preserved ejection fraction. $N$ Engl J Med, 359, 24562467.

Matsui, Y., Takagi, H., Qu, X., Abdellatif, M., Sakoda, H., Asano, T., et al. (2007). Distinct roles of autophagy in the heart during ischemia and reperfusion: roles of AMP-activated protein kinase and Beclin 1 in mediating autophagy. Circ Res, 100, 914-922.

Mazue, G., Vic, P., Gouy, D., Remandet, B., Lacheretz, F., Berthe, J., et al. (1984). Recovery from amiodarone-induced lipidosis in laboratory animals: a toxicological study. Fundam Appl Toxicol, 4, 992-999.

Mehta, S. R., Yusuf, S., Diaz, R., Zhu, J., Pais, P., Xavier, D., et al. (2005). Effect of glucose-insulinpotassium infusion on mortality in patients with acute ST-segment elevation myocardial infarction: the CREATE-ECLA randomized controlled trial. Jama, 293, 437-446.

Meier, C., Wahllaender, A., Hess, C. W., \& Preisig, R. (1986). Perhexiline-induced lipidosis in the dark Agouti (DA) rat. An animal model of genetically determined neurotoxicity. Brain, 109 ( Pt 4), 649660. 
Merritt, M. E., Harrison, C., Storey, C., Jeffrey, F. M., Sherry, A. D., \& Malloy, C. R. (2007). Hyperpolarized $13 \mathrm{C}$ allows a direct measure of flux through a single enzyme-catalyzed step by NMR. Proc Natl Acad Sci U S A, 104, 19773-19777.

Milstien, S., \& Katusic, Z. (1999). Oxidation of tetrahydrobiopterin by peroxynitrite: implications for vascular endothelial function. Biochem Biophys Res Commun, 263, 681-684.

Morgan, M. Y., Reshef, R., Shah, R. R., Oates, N. S., Smith, R. L., \& Sherlock, S. (1984). Impaired oxidation of debrisoquine in patients with perhexiline liver injury. Gut, 25, 1057-1064.

Morisco, C., Nappi, A., Argenziano, L., Sarno, D., Fonatana, D., Imbriaco, M., et al. (1994). Noninvasive evaluation of cardiac hemodynamics during exercise in patients with chronic heart failure: effects of short-term coenzyme Q10 treatment. Mol Aspects Med, 15 Suppl, s155-163.

Mortensen, S. A., Rosenfeldt, F., Kumar, A., Dolliner, P., Filipiak, K. J., Pella, D., et al. (2014). The effect of coenzyme Q10 on morbidity and mortality in chronic heart failure: results from Q-SYMBIO: a randomized double-blind trial. JACC Heart Fail, 2, 641-649.

Munkholm, H., Hansen, H. H., \& Rasmussen, K. (1999). Coenzyme Q10 treatment in serious heart failure. Biofactors, 9, 285-289.

Munzel, T., Gori, T., Keaney, J. F., Jr., Maack, C., \& Daiber, A. (2015). Pathophysiological role of oxidative stress in systolic and diastolic heart failure and its therapeutic implications. Eur Heart J, 36, 2555-2564.

Murray, A. J., Anderson, R. E., Watson, G. C., Radda, G. K., \& Clarke, K. (2004). Uncoupling proteins in human heart. Lancet, 364, 1786-1788.

Murray, G. L., \& Colombo, J. (2014). Ranolazine preserves and improves left ventricular ejection fraction and autonomic measures when added to guideline-driven therapy in chronic heart failure. Heart Int, 9, 66-73.

Nadruz, W., Jr., West, E., Santos, M., Skali, H., Groarke, J. D., Forman, D. E., et al. (2016). Heart Failure and Midrange Ejection Fraction: Implications of Recovered Ejection Fraction for Exercise Tolerance and Outcomes. Circ Heart Fail, 9, e002826.

Najjar, S. S., Schulman, S. P., Gerstenblith, G., Fleg, J. L., Kass, D. A., O'Connor, F., et al. (2004). Age and gender affect ventricular-vascular coupling during aerobic exercise. J Am Coll Cardiol, 44, 611617.

Nathanson, D., Ullman, B., Lofstrom, U., Hedman, A., Frick, M., Sjoholm, A., et al. (2012). Effects of intravenous exenatide in type 2 diabetic patients with congestive heart failure: a double-blind, randomised controlled clinical trial of efficacy and safety. Diabetologia, 55, 926-935.

Neglia, D., De Caterina, A., Marraccini, P., Natali, A., Ciardetti, M., Vecoli, C., et al. (2007). Impaired myocardial metabolic reserve and substrate selection flexibility during stress in patients with idiopathic dilated cardiomyopathy. Am J Physiol Heart Circ Physiol, 293, H3270-3278.

Nemoto, S., Fergusson, M. M., \& Finkel, T. (2004). Nutrient availability regulates SIRT1 through a forkhead-dependent pathway. Science, 306, 2105-2108.

Neri, R., Mestroni, L., Salvi, A., Pandullo, C., \& Camerini, F. (1987). Ventricular arrhythmias in dilated cardiomyopathy: efficacy of amiodarone. Am Heart J, 113, 707-715. 
Nesto, R. W., Bell, D., Bonow, R. O., Fonseca, V., Grundy, S. M., Horton, E. S., et al. (2003). Thiazolidinedione use, fluid retention, and congestive heart failure: a consensus statement from the American Heart Association and American Diabetes Association. October 7, 2003. Circulation, 108, 2941-2948.

Neubauer, S. (2007). The failing heart--an engine out of fuel. N Engl J Med, 356, 1140-1151.

Neubauer, S., Horn, M., Cramer, M., Harre, K., Newell, J. B., Peters, W., et al. (1997). Myocardial phosphocreatine-to-ATP ratio is a predictor of mortality in patients with dilated cardiomyopathy. Circulation, 96, 2190-2196.

Neubauer, S., Krahe, T., Schindler, R., Horn, M., Hillenbrand, H., Entzeroth, C., et al. (1992). 31P magnetic resonance spectroscopy in dilated cardiomyopathy and coronary artery disease. Altered cardiac high-energy phosphate metabolism in heart failure. Circulation, 86, 1810-1818.

Neubauer, S., Remkes, H., Spindler, M., Horn, M., Wiesmann, F., Prestle, J., et al. (1999). Downregulation of the $\mathrm{Na}(+)$-creatine cotransporter in failing human myocardium and in experimental heart failure. Circulation, 100, 1847-1850.

Ngo, D. T., Drury, N. E., Pagano, D., Frenneaux, M. P., \& Horowitz, J. D. (2011). Abstract 14461: How Does Perhexiline Modulate Myocardial Energetics and Ameliorate Redox Stress? Circulation, 124, A14461-A14461.

Nicklas, J. M., McKenna, W. J., Stewart, R. A., Mickelson, J. K., Das, S. K., Schork, M. A., et al. (1991). Prospective, double-blind, placebo-controlled trial of low-dose amiodarone in patients with severe heart failure and asymptomatic frequent ventricular ectopy. Am Heart J, 122, 1016-1021.

Nicolas-Robin, A., Amour, J., Ibanez-Esteve, C., Coriat, P., Riou, B., \& Langeron, O. (2008). Effect of glucose-insulin-potassium in severe acute heart failure after brain death. Crit Care Med, 36, 27402745.

O'Donnell, J. M., Fields, A. D., Sorokina, N., \& Lewandowski, E. D. (2008). The absence of endogenous lipid oxidation in early stage heart failure exposes limits in lipid storage and turnover. $J \mathrm{Mol} \mathrm{Cell}$ Cardiol, 44, 315-322.

Obokata, M., Kane, G. C., Reddy, Y. N., Olson, T. P., Melenovsky, V., \& Borlaug, B. A. (2016). The Role of Diastolic Stress Testing in the Evaluation for HFpEF:A Simultaneous Invasive-Echocardiographic Study. Circulation.

Oka, S., Zhai, P., Yamamoto, T., Ikeda, Y., Byun, J., Hsu, C. P., et al. (2015). Peroxisome Proliferator Activated Receptor-alpha Association With Silent Information Regulator 1 Suppresses Cardiac Fatty Acid Metabolism in the Failing Heart. Circ Heart Fail, 8, 1123-1132.

Oleck, S., \& Ventura, H. O. (2016). Coenzyme Q10 and Utility in Heart Failure: Just Another Supplement? Curr Heart Fail Rep, 13, 190-195.

Ono, H., Ohara, N., \& Hashimoto, K. (1982). Effect of an antianginal drug, perhexiline, on myocardial oxygen consumption in anesthetized open-chest dogs compared with verapamil and glyceryl trinitrate. Jpn Circ J, 46, 559-567.

Osorio, J. C., Stanley, W. C., Linke, A., Castellari, M., Diep, Q. N., Panchal, A. R., et al. (2002). Impaired myocardial fatty acid oxidation and reduced protein expression of retinoid $\mathrm{X}$ receptor-alpha in pacing-induced heart failure. Circulation, 106, 606-612. 
Owan, T. E., Hodge, D. O., Herges, R. M., Jacobsen, S. J., Roger, V. L., \& Redfield, M. M. (2006). Trends in prevalence and outcome of heart failure with preserved ejection fraction. $N$ Engl J Med, 355, 251-259.

Pacher, P., Liaudet, L., Bai, P., Virag, L., Mabley, J. G., Hasko, G., et al. (2002). Activation of poly(ADPribose) polymerase contributes to development of doxorubicin-induced heart failure. $J$ Pharmacol Exp Ther, 300, 862-867.

Pacher, P., \& Szabo, C. (2007). Role of poly(ADP-ribose) polymerase 1 (PARP-1) in cardiovascular diseases: the therapeutic potential of PARP inhibitors. Cardiovasc Drug Rev, 25, 235-260.

Palacios, O. M., Carmona, J. J., Michan, S., Chen, K. Y., Manabe, Y., Ward, J. L., 3rd, et al. (2009). Diet and exercise signals regulate SIRT3 and activate AMPK and PGC-1alpha in skeletal muscle. Aging (Albany NY), 1, 771-783.

Paolisso, G., Gambardella, A., Galzerano, D., D'Amore, A., Rubino, P., Verza, M., et al. (1994). Totalbody and myocardial substrate oxidation in congestive heart failure. Metabolism, 43, 174-179.

Pascual, F., \& Coleman, R. A. (2016). Fuel availability and fate in cardiac metabolism: A tale of two substrates. Biochim Biophys Acta, 1860, 1425-1433.

Paul, M., Poyan Mehr, A., \& Kreutz, R. (2006). Physiology of local renin-angiotensin systems. Physiol Rev, 86, 747-803.

Paulus, W. J., \& Tschope, C. (2013). A novel paradigm for heart failure with preserved ejection fraction: comorbidities drive myocardial dysfunction and remodeling through coronary microvascular endothelial inflammation. J Am Coll Cardiol, 62, 263-271.

Pellieux, C., Aasum, E., Larsen, T. S., Montessuit, C., Papageorgiou, I., Pedrazzini, T., et al. (2006). Overexpression of angiotensinogen in the myocardium induces downregulation of the fatty acid oxidation pathway. J Mol Cell Cardiol, 41, 459-466.

Phan, T. T., Abozguia, K., Nallur Shivu, G., Mahadevan, G., Ahmed, I., Williams, L., et al. (2009). Heart failure with preserved ejection fraction is characterized by dynamic impairment of active relaxation and contraction of the left ventricle on exercise and associated with myocardial energy deficiency. $J$ Am Coll Cardiol, 54, 402-409.

Phuong, H., Choi, B. Y., Chong, C. R., Raman, B., \& Horowitz, J. D. (2016). Can Perhexiline Be Utilized Without Long-Term Toxicity? A Clinical Practice Audit. Ther Drug Monit, 38, 73-78.

Pillai, J. B., Isbatan, A., Imai, S., \& Gupta, M. P. (2005). Poly(ADP-ribose) polymerase-1-dependent cardiac myocyte cell death during heart failure is mediated by NAD+ depletion and reduced Sir2alpha deacetylase activity. J Biol Chem, 280, 43121-43130.

Ponikowski, P., Voors, A. A., Anker, S. D., Bueno, H., Cleland, J. G., Coats, A. J., et al. (2016). 2016 ESC Guidelines for the diagnosis and treatment of acute and chronic heart failure: The Task Force for the diagnosis and treatment of acute and chronic heart failure of the European Society of Cardiology (ESC). Developed with the special contribution of the Heart Failure Association (HFA) of the ESC. Eur J Heart Fail, 18, 891-975.

Prabu, S. K., Anandatheerthavarada, H. K., Raza, H., Srinivasan, S., Spear, J. F., \& Avadhani, N. G. (2006). Protein kinase A-mediated phosphorylation modulates cytochrome c oxidase function and augments hypoxia and myocardial ischemia-related injury. J Biol Chem, 281, 2061-2070. 
Price, N. L., Gomes, A. P., Ling, A. J., Duarte, F. V., Martin-Montalvo, A., North, B. J., et al. (2012). SIRT1 is required for AMPK activation and the beneficial effects of resveratrol on mitochondrial function. Cell Metab, 15, 675-690.

Puigserver, P., Wu, Z., Park, C. W., Graves, R., Wright, M., \& Spiegelman, B. M. (1998). A coldinducible coactivator of nuclear receptors linked to adaptive thermogenesis. Cell, 92, 829-839.

Randle, P. J., Garland, P. B., Hales, C. N., \& Newsholme, E. A. (1963). The glucose fatty-acid cycle. Its role in insulin sensitivity and the metabolic disturbances of diabetes mellitus. Lancet, 1, 785-789.

Regitz, V., Bossaller, C., Strasser, R., Muller, M., Shug, A. L., \& Fleck, E. (1990). Metabolic alterations in end-stage and less severe heart failure--myocardial carnitine decrease. $J$ Clin Chem Clin Biochem, 28, 611-617.

Revenco, D., \& Morgan, J. P. (2009). Metabolic modulation and cellular therapy of cardiac dysfunction and failure. J Cell Mol Med, 13, 811-825.

Riehle, C., Wende, A. R., Zaha, V. G., Pires, K. M., Wayment, B., Olsen, C., et al. (2011). PGC-1beta deficiency accelerates the transition to heart failure in pressure overload hypertrophy. Circ Res, 109, 783-793.

Rodgers, J. T., Lerin, C., Haas, W., Gygi, S. P., Spiegelman, B. M., \& Puigserver, P. (2005). Nutrient control of glucose homeostasis through a complex of PGC-1alpha and SIRT1. Nature, 434, 113-118.

Rosca, M. G., \& Hoppel, C. L. (2013). Mitochondrial dysfunction in heart failure. Heart Fail Rev, 18, 607-622.

Sabbah, H. N., Gupta, R. C., Kohli, S., Wang, M., Hachem, S., \& Zhang, K. (2016). Chronic Therapy With Elamipretide (MTP-131), a Novel Mitochondria-Targeting Peptide, Improves Left Ventricular and Mitochondrial Function in Dogs With Advanced Heart Failure. Circ Heart Fail, 9, e002206.

Sack, M. N., Rader, T. A., Park, S., Bastin, J., McCune, S. A., \& Kelly, D. P. (1996). Fatty acid oxidation enzyme gene expression is downregulated in the failing heart. Circulation, 94, 2837-2842.

Samovski, D., Sun, J., Pietka, T., Gross, R. W., Eckel, R. H., Su, X., et al. (2015). Regulation of AMPK activation by CD36 links fatty acid uptake to beta-oxidation. Diabetes, 64, 353-359.

Sander, S., Coleman, C. I., Patel, A. A., Kluger, J., \& White, C. M. (2006). The impact of coenzyme Q10 on systolic function in patients with chronic heart failure. J Card Fail, 12, 464-472.

Sarma, S., Ardehali, H., \& Gheorghiade, M. (2012). Enhancing the metabolic substrate: PPAR-alpha agonists in heart failure. Heart Fail Rev, 17, 35-43.

Sasaki, H., Asanuma, H., Fujita, M., Takahama, H., Wakeno, M., Ito, S., et al. (2009). Metformin prevents progression of heart failure in dogs: role of AMP-activated protein kinase. Circulation, 119, 2568-2577.

Scheubel, R. J., Tostlebe, M., Simm, A., Rohrbach, S., Prondzinsky, R., Gellerich, F. N., et al. (2002). Dysfunction of mitochondrial respiratory chain complex I in human failing myocardium is not due to disturbed mitochondrial gene expression. J Am Coll Cardiol, 40, 2174-2181.

Scheurle, C., Dammrich, M., Becker, J. U., \& Baumgartel, M. W. (2014). Renal phospholipidosis possibly induced by ranolazine. Clin Kidney J, 7, 62-64. 
Schmidt-Schweda, S., \& Holubarsch, C. (2000). First clinical trial with etomoxir in patients with chronic congestive heart failure. Clin Sci (Lond), 99, 27-35.

Schonfeld, P., \& Wojtczak, L. (2007). Fatty acids decrease mitochondrial generation of reactive oxygen species at the reverse electron transport but increase it at the forward transport. Biochim Biophys Acta, 1767, 1032-1040.

Schrauwen, P., Saris, W. H., \& Hesselink, M. K. (2001). An alternative function for human uncoupling protein 3: protection of mitochondria against accumulation of nonesterified fatty acids inside the mitochondrial matrix. Faseb j, 15, 2497-2502.

Schwartzenberg, S., Redfield, M. M., From, A. M., Sorajja, P., Nishimura, R. A., \& Borlaug, B. A. (2012). Effects of vasodilation in heart failure with preserved or reduced ejection fraction implications of distinct pathophysiologies on response to therapy. J Am Coll Cardiol, 59, 442-451.

Schwarz, K., Siddiqi, N., Singh, S., Neil, C. J., Dawson, D. K., \& Frenneaux, M. P. (2014). The breathing heart - mitochondrial respiratory chain dysfunction in cardiac disease. Int J Cardiol, 171, 134-143.

Shah, D. D., Fonarow, G. C., \& Horwich, T. B. (2010). Metformin therapy and outcomes in patients with advanced systolic heart failure and diabetes. J Card Fail, 16, 200-206.

Shah, R. R., Oates, N. S., Idle, J. R., Smith, R. L., \& Lockhart, J. D. (1982). Impaired oxidation of debrisoquine in patients with perhexiline neuropathy. Br Med J (Clin Res Ed), 284, 295-299.

Shah, S. J., Kitzman, D. W., Borlaug, B. A., van Heerebeek, L., Zile, M. R., Kass, D. A., et al. (2016). Phenotype-Specific Treatment of Heart Failure With Preserved Ejection Fraction: A Multiorgan Roadmap. Circulation, 134, 73-90.

Sharma, A., Fonarow, G. C., Butler, J., Ezekowitz, J. A., \& Felker, G. M. (2016). Coenzyme Q10 and Heart Failure: A State-of-the-Art Review. Circ Heart Fail, 9, e002639.

Sharma, K., \& Kass, D. A. (2014). Heart failure with preserved ejection fraction: mechanisms, clinical features, and therapies. Circ Res, 115, 79-96.

Sharma, N. M., Cunningham, C. J., Zheng, H., Liu, X., \& Patel, K. P. (2016). Hypoxia-Inducible Factor1alpha Mediates Increased Sympathoexcitation via Glutamatergic N-Methyl-d-Aspartate Receptors in the Paraventricular Nucleus of Rats With Chronic Heart Failure. Circ Heart Fail, 9.

Shibayama, J., Yuzyuk, T. N., Cox, J., Makaju, A., Miller, M., Lichter, J., et al. (2015). Metabolic remodeling in moderate synchronous versus dyssynchronous pacing-induced heart failure: integrated metabolomics and proteomics study. PLoS One, 10, e0118974.

Siddiqi, N., Singh, S., Beadle, R., Dawson, D., \& Frenneaux, M. (2013). Cardiac metabolism in hypertrophy and heart failure: implications for therapy. Heart Fail Rev, 18, 595-606.

Singh, A. P., Singh, R., \& Krishan, P. (2015). Ameliorative role of gemfibrozil against partial abdominal aortic constriction-induced cardiac hypertrophy in rats. Cardiol Young, 25, 725-730.

Singh SN, Fletcher RD, Fisher SG, Singh BN, Lewis HD, Deedwania PC, Massie BM, Colling C, Lazzeri D. Amiodarone in patients with congestive heart failure and asymptomatic ventricular arrhythmia. Survival Trial of Antiarrhythmic Therapy in Congestive Heart Failure. N Engl J Med. 1995 Jul 13;333(2):77-82. 
Smith, C. S., Bottomley, P. A., Schulman, S. P., Gerstenblith, G., \& Weiss, R. G. (2006). Altered creatine kinase adenosine triphosphate kinetics in failing hypertrophied human myocardium. Circulation, 114, 1151-1158.

Sokos, G. G., Nikolaidis, L. A., Mankad, S., Elahi, D., \& Shannon, R. P. (2006). Glucagon-like peptide-1 infusion improves left ventricular ejection fraction and functional status in patients with chronic heart failure. J Card Fail, 12, 694-699.

Solomon, S. D., Anavekar, N., Skali, H., McMurray, J. J., Swedberg, K., Yusuf, S., et al. (2005). Influence of ejection fraction on cardiovascular outcomes in a broad spectrum of heart failure patients. Circulation, 112, 3738-3744.

Sorokina, N., O'Donnell, J. M., McKinney, R. D., Pound, K. M., Woldegiorgis, G., LaNoue, K. F., et al. (2007). Recruitment of compensatory pathways to sustain oxidative flux with reduced carnitine palmitoyltransferase I activity characterizes inefficiency in energy metabolism in hypertrophied hearts. Circulation, 115, 2033-2041.

Stanley, W. C., Recchia, F. A., \& Lopaschuk, G. D. (2005). Myocardial substrate metabolism in the normal and failing heart. Physiol Rev, 85, 1093-1129.

Stapel, B., Kohlhaas, M., Ricke-Hoch, M., Haghikia, A., Erschow, S., Knuuti, J., et al. (2016). Low STAT3 expression sensitizes to toxic effects of beta-adrenergic receptor stimulation in peripartum cardiomyopathy. Eur Heart J. Feb 1;38 (5):349-361.

Sumimoto, T., Jikuhara, T., Hattori, T., Yuasa, F., Kaida, M., Hikosaka, M., et al. (1997). Importance of left ventricular diastolic function on maintenance of exercise capacity in patients with systolic dysfunction after anterior myocardial infarction. Am Heart J, 133, 87-93.

Sun, Y., Li, T., Xie, C., Zhang, Y., Zhou, K., Wang, X., et al. (2016). Dichloroacetate treatment improves mitochondrial metabolism and reduces brain injury in neonatal mice. Oncotarget, 7, 31708-31722.

Sundaresan, N. R., Vasudevan, P., Zhong, L., Kim, G., Samant, S., Parekh, V., et al. (2012). The sirtuin SIRT6 blocks IGF-Akt signaling and development of cardiac hypertrophy by targeting c-Jun. Nat Med, $18,1643-1650$.

Suner, A., \& Cetin, M. (2016). The effect of trimetazidine on ventricular repolarization indexes and left ventricular diastolic function in patients with coronary slow flow. Coron Artery Dis, 27, 398-404.

Szeto, H. H. (2014). First-in-class cardiolipin-protective compound as a therapeutic agent to restore mitochondrial bioenergetics. Br J Pharmacol, 171, 2029-2050.

Tan, Y. T., Wenzelburger, F., Lee, E., Heatlie, G., Leyva, F., Patel, K., et al. (2009). The pathophysiology of heart failure with normal ejection fraction: exercise echocardiography reveals complex abnormalities of both systolic and diastolic ventricular function involving torsion, untwist, and longitudinal motion. J Am Coll Cardiol, 54, 36-46.

Tang, Y., Mi, C., Liu, J., Gao, F., \& Long, J. (2014). Compromised mitochondrial remodeling in compensatory hypertrophied myocardium of spontaneously hypertensive rat. Cardiovasc Pathol, 23, 101-106.

Tanno, M., Kuno, A., Yano, T., Miura, T., Hisahara, S., Ishikawa, S., et al. (2010). Induction of manganese superoxide dismutase by nuclear translocation and activation of SIRT1 promotes cell survival in chronic heart failure. J Biol Chem, 285, 8375-8382. 
Tenenbaum, A., \& Fisman, E. Z. (2004). Impaired glucose metabolism in patients with heart failure: pathophysiology and possible treatment strategies. Am J Cardiovasc Drugs, 4, 269-280.

Torp-Pedersen, C., Metra, M., Spark, P., Lukas, M. A., Moullet, C., Scherhag, A., et al. (2007). The safety of amiodarone in patients with heart failure. J Card Fail, 13, 340-345.

Tsutsui, H., Kinugawa, S., \& Matsushima, S. (2011). Oxidative stress and heart failure. Am J Physiol Heart Circ Physiol, 301, H2181-2190.

Turcani, M., \& Rupp, H. (1997). Etomoxir improves left ventricular performance of pressureoverloaded rat heart. Circulation, 96, 3681-3686.

Turcani, M., \& Rupp, H. (1999). Modification of left ventricular hypertrophy by chronic etomixir treatment. BrJ Pharmacol, 126, 501-507.

Tuunanen, H., Engblom, E., Naum, A., Nagren, K., Scheinin, M., Hesse, B., et al. (2008). Trimetazidine, a metabolic modulator, has cardiac and extracardiac benefits in idiopathic dilated cardiomyopathy. Circulation, 118, 1250-1258.

Unger, S. A., Kennedy, J. A., McFadden-Lewis, K., Minerds, K., Murphy, G. A., \& Horowitz, J. D. (2005). Dissociation between metabolic and efficiency effects of perhexiline in normoxic rat myocardium. $J$ Cardiovasc Pharmacol, 46, 849-855.

Unger, S. A., Robinson, M. A., \& Horowitz, J. D. (1997). Perhexiline improves symptomatic status in elderly patients with severe aortic stenosis. Aust N Z J Med, 27, 24-28.

Ussher, J. R., Jaswal, J. S., \& Lopaschuk, G. D. (2012). Pyridine nucleotide regulation of cardiac intermediary metabolism. Circ Res, 111, 628-641.

van der Vusse, G. J., van Bilsen, M., \& Glatz, J. F. (2000). Cardiac fatty acid uptake and transport in health and disease. Cardiovasc Res, 45, 279-293.

van Heerebeek, L., Borbely, A., Niessen, H. W., Bronzwaer, J. G., van der Velden, J., Stienen, G. J., et al. (2006). Myocardial structure and function differ in systolic and diastolic heart failure. Circulation, $113,1966-1973$.

van Heerebeek, L., Hamdani, N., Falcao-Pires, I., Leite-Moreira, A. F., Begieneman, M. P., Bronzwaer, J. G., et al. (2012). Low myocardial protein kinase $G$ activity in heart failure with preserved ejection fraction. Circulation, 126, 830-839.

van Riet, E. E., Hoes, A. W., Wagenaar, K. P., Limburg, A., Landman, M. A., \& Rutten, F. H. (2016). Epidemiology of heart failure: the prevalence of heart failure and ventricular dysfunction in older adults over time. A systematic review. Eur J Heart Fail, 18, 242-252.

Ventura-Clapier, R., Garnier, A., Veksler, V., \& Joubert, F. (2011). Bioenergetics of the failing heart. Biochim Biophys Acta, 1813, 1360-1372.

Vik-Mo, H., Mjos, O. D., Neely, J. R., Maroko, P. R., \& Ribeiro, L. G. (1986). Limitation of myocardial infarct size by metabolic interventions that reduce accumulation of fatty acid metabolites in ischemic myocardium. Am Heart J, 111, 1048-1054. 
von Lueder, T. G., Sangaralingham, S. J., Wang, B. H., Kompa, A. R., Atar, D., Burnett, J. C., Jr., et al. (2013). Renin-angiotensin blockade combined with natriuretic peptide system augmentation: novel therapeutic concepts to combat heart failure. Circ Heart Fail, 6, 594-605.

Wang, C. H., Wang, S. S., Ko, W. J., Chen, Y. S., Chang, C. Y., Chang, R. W., et al. (2013). Acetyl-Icarnitine and oxfenicine on cardiac pumping mechanics in streptozotocin-induced diabetes in male Wistar rats. PLoS One, 8, e69977.

Westermann, D., Lindner, D., Kasner, M., Zietsch, C., Savvatis, K., Escher, F., et al. (2011). Cardiac inflammation contributes to changes in the extracellular matrix in patients with heart failure and normal ejection fraction. Circ Heart Fail, 4, 44-52.

Worthley, M. I., Holmes, A. S., Willoughby, S. R., Kucia, A. M., Heresztyn, T., Stewart, S., et al. (2007). The deleterious effects of hyperglycemia on platelet function in diabetic patients with acute coronary syndromes mediation by superoxide production, resolution with intensive insulin administration. J Am Coll Cardiol, 49, 304-310.

Wroge, J., \& Williams, N. T. (2016). Glucagon-Like Peptide-1 (GLP-1) Receptor Agonists in Cardiac Disorders. Ann Pharmacother, 50, 1041-1050.

Wu, H., Zhu, Q., Cai, M., Tong, X., Liu, D., Huang, J., et al. (2014). Effect of inhibiting malonyl-CoA decarboxylase on cardiac remodeling after myocardial infarction in rats. Cardiology, 127, 236-244.

Wu, P., Peters, J. M., \& Harris, R. A. (2001). Adaptive increase in pyruvate dehydrogenase kinase 4 during starvation is mediated by peroxisome proliferator-activated receptor alpha. Biochem Biophys Res Commun, 287, 391-396.

Xiao, H., Ma, X., Feng, W., Fu, Y., Lu, Z., Xu, M., et al. (2010). Metformin attenuates cardiac fibrosis by inhibiting the TGFbeta1-Smad3 signalling pathway. Cardiovasc Res, 87, 504-513.

Xiong, Q., Zhang, P., Guo, J., Swingen, C., Jang, A., \& Zhang, J. (2015). Myocardial ATP hydrolysis rates in vivo: a porcine model of pressure overload-induced hypertrophy. Am J Physiol Heart Circ Physiol, $309, \mathrm{H} 450-458$.

Yancy, C. W., Jessup, M., Bozkurt, B., Butler, J., Casey, D. E., Jr., Drazner, M. H., et al. (2013). 2013 ACCF/AHA guideline for the management of heart failure: a report of the American College of Cardiology Foundation/American Heart Association Task Force on Practice Guidelines. J Am Coll Cardiol, 62, e147-239.

Yancy, C. W., Lopatin, M., Stevenson, L. W., De Marco, T., \& Fonarow, G. C. (2006). Clinical presentation, management, and in-hospital outcomes of patients admitted with acute decompensated heart failure with preserved systolic function: a report from the Acute Decompensated Heart Failure National Registry (ADHERE) Database. J Am Coll Cardiol, 47, 76-84.

Yao, H., Han, X., \& Han, X. (2014). The cardioprotection of the insulin-mediated PI3K/Akt/mTOR signaling pathway. Am J Cardiovasc Drugs, 14, 433-442.

Yazaki, Y., Isobe, M., Takahashi, W., Kitabayashi, H., Nishiyama, O., Sekiguchi, M., et al. (1999). Assessment of myocardial fatty acid metabolic abnormalities in patients with idiopathic dilated cardiomyopathy using 123I BMIPP SPECT: correlation with clinicopathological findings and clinical course. Heart, 81, 153-159. 
Yin, M., van der Horst, I. C., van Melle, J. P., Qian, C., van Gilst, W. H., Sillje, H. H., et al. (2011). Metformin improves cardiac function in a nondiabetic rat model of post-MI heart failure. Am J Physiol Heart Circ Physiol, 301, H459-468.

Yin, W. H., Chen, J. W., Chen, Y. H., \& Lin, S. J. (2013). Fenofibrate Modulates HO-1 and Ameliorates Endothelial Expression of Cell Adhesion Molecules in Systolic Heart Failure. Acta Cardiol Sin, 29, 251260.

Yin, X., Dwyer, J., Langley, S. R., Mayr, U., Xing, Q., Drozdov, I., et al. (2013). Effects of perhexilineinduced fuel switch on the cardiac proteome and metabolome. J Mol Cell Cardiol, 55, 27-30.

Yoshioka, J., Chutkow, W. A., Lee, S., Kim, J. B., Yan, J., Tian, R., et al. (2012). Deletion of thioredoxininteracting protein in mice impairs mitochondrial function but protects the myocardium from ischemia-reperfusion injury. J Clin Invest, 122, 267-279.

Yusuf, S., Pfeffer, M. A., Swedberg, K., Granger, C. B., Held, P., McMurray, J. J., et al. (2003). Effects of candesartan in patients with chronic heart failure and preserved left-ventricular ejection fraction: the CHARM-Preserved Trial. Lancet, 362, 777-781.

Zaha, V. G., \& Young, L. H. (2012). AMP-activated protein kinase regulation and biological actions in the heart. Circ Res, 111, 800-814.

Zander, M., Madsbad, S., Madsen, J. L., \& Holst, J. J. (2002). Effect of 6-week course of glucagon-like peptide 1 on glycaemic control, insulin sensitivity, and beta-cell function in type 2 diabetes: a parallel-group study. Lancet, 359, 824-830.

Zhabyeyev, P., Gandhi, M., Mori, J., Basu, R., Kassiri, Z., Clanachan, A., et al. (2013). Pressureoverload-induced heart failure induces a selective reduction in glucose oxidation at physiological afterload. Cardiovasc Res, 97, 676-685.

Zhang, L., Lu, Y., Jiang, H., Zhang, L., Sun, A., Zou, Y., et al. (2012). Additional use of trimetazidine in patients with chronic heart failure: a meta-analysis. J Am Coll Cardiol, 59, 913-922.

Zou, D., Geng, N., Chen, Y., Ren, L., Liu, X., Wan, J., et al. (2016). Ranolazine improves oxidative stress and mitochondrial function in the atrium of acetylcholine- $\mathrm{CaCl} 2$ induced atrial fibrillation rats. Life Sci, 156, 7-14. 